\title{
Water lubrication of graphene oxide-based materials
}

\author{
Shaoqing XUE ${ }^{1,2}$, Hanglin $\mathbf{L I}^{1,3}$, Yumei GUO ${ }^{1}$, Baohua ZHANG ${ }^{2}$, Jiusheng LI $^{1}$, Xiangqiong ZENG ${ }^{1, *}$ \\ ${ }^{1}$ Laboratory for Advanced Lubricating Materials, Shanghai Advanced Research Institute, Chinese Academy of Sciences, University of \\ Chinese Academy of Sciences, Shanghai 201210, China \\ ${ }^{2}$ School of Environmental and Chemical Engineering, Shanghai University, Shanghai 200444, China \\ ${ }^{3}$ Key Laboratory for Advanced Materials, School of Chemistry and Molecular Engineering, East China University of Science and \\ Technology, Shanghai 200237, China
}

Received: 19 March 2021 / Revised: 10 June 2021 / Accepted: 04 July 2021

(C) The author(s) 2021 .

\begin{abstract}
Water is as an economic, eco-friendly, and efficient lubricant that has gained widespread attention for manufacturing. Using graphene oxide (GO)-based materials can improve the lubricant efficacy of water lubrication due to their outstanding mechanical properties, water dispersibility, and broad application scenarios. In this review, we offer a brief introduction about the background of water lubrication and GO. Subsequently, the synthesis, structure, and lubrication theory of GO are analyzed. Particular attention is focused on the relationship between $\mathrm{pH}$, concentration, and lubrication efficacy when discussing the tribology behaviors of pristine GO. By compounding or reacting GO with various modifiers, amounts of GO-composites are synthesized and applied as lubricant additives or into frictional pairs for different usage scenarios. These various strategies of GO-composite generate interesting effects on the tribology behaviors. Several application cases of GO-based materials are described in water lubrication, including metal processing and bio-lubrication. The advantages and drawbacks of GO-composites are then discussed. The development of GO-based materials for water lubrication is described including some challenges.
\end{abstract}

Keywords: tribology; water lubrication; graphene oxide (GO)

\section{Introduction}

The transformation and upgrading of manufacturing have changed the traditional industrial features. Highquality, economic, clean, and flexible production is the final goal. Efficient lubrication plays an important role. Friction loss is widespread in industrial production taking up to $33 \%$ of industrial energy consumption and $80 \%$ of component failure [1]. Commonly used lubricants are oil-based but they have higher production costs and environmental concern. Therefore, there is an urgent need to find economic, eco-friendly, and efficient lubricants.

Water-based lubricants have economic and environmentally friendly characteristics and have attracted great attention and expectation, but they also have drawbacks in term of friction reduction and loadbearing capacity. To solve these defects and expand the application scenarios, many schemes have been proposed to enhance performance in water lubrication. Of these, the addition of nanoparticles is one of the most promising ways because of its low cost, environmental friendliness, and superior improvement in lubrication. Various nanoparticles have been developed and applied gradually in water lubrication, including carbon nano tube $(\mathrm{CNT}), \mathrm{SiO}_{2}$, $\mathrm{Al}_{2} \mathrm{O}_{3}$, graphene oxide (GO) and so on. Table 1 listed the performance of some typical nanoparticles applied in water lubrication.

Graphene with 2D grid structures has received

* Corresponding author: Xiangqiong ZENG, E-mail: zengxq@sari.ac.cn 
Table 1 The performance of some typical nanoparticles applied in water lubrication.

\begin{tabular}{|c|c|c|c|c|c|c|}
\hline $\begin{array}{c}\text { Additives in water } \\
\text { lubrication }\end{array}$ & $\begin{array}{l}\text { Optimum } \\
\text { concentration }\end{array}$ & $\begin{array}{l}\text { Reduce in COF, } \\
\text { wear, and others }\end{array}$ & Frictional pairs & Test conditions & Test mode & Ref. \\
\hline $\begin{array}{l}\text { Ionic liquid modified } \\
\text { muti-walled CNTs }\end{array}$ & $0.015 \mathrm{wt} \%$ & $\begin{array}{c}\text { COF: } 42 \% \text { (from } \\
0.3 \text { to } 0.174 \text { ) } \\
\text { Wear } 72 \%\end{array}$ & Balls: AISI52100 steel & $\begin{array}{l}\text { Velocity: } 600 \mathrm{rpm} \\
\text { Load: } 20-50 \mathrm{~N}\end{array}$ & Four balls & [13] \\
\hline $\begin{array}{l}\text { Urea modified } \\
\text { fluorinated CNTs }\end{array}$ & $0.015 \mathrm{wt} \%$ & $\begin{array}{c}\text { COF: } 80.86 \% \text { (from } \\
0.33 \text { to } 0.063 \text { ) } \\
\text { Wear: } 96.7 \%\end{array}$ & Balls: GCr15 & $\begin{array}{c}\text { Velocity: } 200-400 \mathrm{rpm} \\
\text { Load: } 3-7 \mathrm{~N}\end{array}$ & $\begin{array}{l}\text { Ball on disk } \\
\text { rotation }\end{array}$ & [14] \\
\hline Modified $\mathrm{SiO}_{2}$ & $5 \mathrm{wt} \%$ & $\begin{array}{c}\text { COF: } 38.3 \% \text { (from } \\
0.071 \text { to } 0.043 \text { ) } \\
\text { Running-in time: } \\
49.4 \%\end{array}$ & $\begin{array}{l}\text { Balls and plates: } \\
\text { carbon nitride }\end{array}$ & $\begin{array}{c}\text { Velocity: } 207 \mathrm{rpm} \\
\text { Temperature: Room } \\
\text { temperature (RT) } \\
\text { Load: } 30 \mathrm{~N}\end{array}$ & $\begin{array}{l}\text { Ball on disk } \\
\text { rotation }\end{array}$ & [15] \\
\hline $\mathrm{TiO}_{2}(\mathrm{P} 25)$ & 0.8 wt $\%$ & $\begin{array}{c}\text { COF: } 50 \% \text { (from } \\
0.3 \text { to } 0.152 \text { ) } \\
\text { Wear: } 68 \%\end{array}$ & $\begin{array}{l}\text { Balls: Cr steel } \\
\text { Plates: low-carbon } \\
\text { microalloyed steel }\end{array}$ & $\begin{array}{c}\text { Velocity: } 13.65,12.74 \text {, } \\
11.94 \mathrm{rpm} \\
\text { Load: } 50 \mathrm{~N} \\
\text { Temperature: RT }\end{array}$ & $\begin{array}{l}\text { Ball on plate } \\
\text { rotation }\end{array}$ & [16] \\
\hline $\begin{array}{c}\mathrm{TiO}_{2}(\mathrm{P} 25) \text { with a } \\
\text { diameter of approx. } \\
20 \mathrm{~nm}\end{array}$ & $4 \mathrm{wt} \%$ & $\begin{array}{c}\text { COF: } 36.4 \% \text { (from } \\
0.29 \text { to } 0.181 \text { ) } \\
\text { Wear: } 18.7 \%\end{array}$ & $\begin{array}{l}\text { Balls: E52100 Cr } \\
\text { Plates: steel and } \\
\text { FSS } 445\end{array}$ & $\begin{array}{c}\text { Velocity: } 34 \mathrm{rpm} \\
\text { Load: } 5 \mathrm{~N} \\
\text { Temperature: } 25^{\circ} \mathrm{C}\end{array}$ & $\begin{array}{l}\text { Ball on plate } \\
\text { rotation }\end{array}$ & [17] \\
\hline $\begin{array}{l}\text { Alcohol modified } \\
\mathrm{Cu} \text { nanoparticle }\end{array}$ & $\begin{array}{l}4 \mathrm{wt} \% \text { for anti- } \\
\text { friction properties; } \\
5 \mathrm{wt} \% \text { for extreme } \\
\text { pressure properties }\end{array}$ & $\begin{array}{l}\text { COF: the lowest } \\
\text { reached } 0.095 \text { under } \\
\text { the load of } 100 \mathrm{~N} \\
\text { Wear: } 52 \%\end{array}$ & $\begin{array}{l}\text { Balls: GCr15- } \\
\text { bearing steel }\end{array}$ & $\begin{array}{c}\text { Velocity: } 1,450 \mathrm{rpm} \\
\text { Load: } 100 \mathrm{~N} \\
\text { Temperature: } 25^{\circ} \mathrm{C}\end{array}$ & Four balls & [18] \\
\hline $\mathrm{Al}_{2} \mathrm{O}_{3}$ & 1 or $2 \mathrm{wt} \%$ & $\begin{array}{c}\text { COF: } 27 \% \text { (from } 0.26 \\
\text { to } 0.23) \\
\text { Wear: } 22 \%\end{array}$ & $\begin{array}{l}\text { Balls: AISI } 52100 \\
\text { alloy steel } \\
\text { Plates: AISI } \\
304 \text { stainless steel }\end{array}$ & $\begin{array}{c}\text { Velocity: } 0.02-0.1 \mathrm{~m} / \mathrm{s} \\
\text { Load: } 10-40 \mathrm{~N}\end{array}$ & $\begin{array}{l}\text { Ball on three } \\
\text { plates }\end{array}$ & [19] \\
\hline $\begin{array}{c}\text { Dopamine-choline } \\
\text { modified } \\
\text { nanodiamond }\end{array}$ & $0.1 \mathrm{wt} \%$ & $\begin{array}{c}\text { COF: } 40 \% \text { (from } \\
0.028 \text { to } 0.017 \text { ) }\end{array}$ & $\begin{array}{l}\text { Balls and plates: steel } \\
\text { grade EN } 52100\end{array}$ & $\begin{array}{c}\text { Velocity: } 360 \mathrm{rpm} \\
\text { Load: } 1 \mathrm{~N} \\
\text { Temperature: } 25^{\circ} \mathrm{C}\end{array}$ & $\begin{array}{l}\text { Ball on plate } \\
\text { rotation }\end{array}$ & [20] \\
\hline
\end{tabular}

great attention from researchers since its appearance, due to excellent thermal conductivity and mechanical performance $[2,3]$. Tribology research also showed that graphene could decrease the coefficient of friction (COF) and exhibit great potential in lubrication fields [4]. For instance, the research of graphene in oil lubrication is widely reported recently [5-7]. However, the aggregation of graphene is one of the biggest challenges in its application.

GO is a derivative of graphene and has equally excellent physical properties. On the contrary, GO performs long-term dispersion stability in water and is considered as ideal water lubrication additives. But it appears more serious aggregation than graphene in non-polar base oil. GO as additives in oil lubrication even causes greater friction than that in base oil. The great dispersion in water is due to the abundant oxygen-containing functional groups on the carbon skeleton such as the epoxy group, hydroxyl group, and carboxyl group. These groups also offer numerous reaction sites for functionalization, which allows researchers to introduce various introduction or functional groups to tailoring the property and performance of GO. These personalized modifications provide great flexibility for different application scenarios.

Here, we review GO in water lubrication. The synthesis strategy and lubrication foundation of GO is introduced first. Subsequently, the tribology behaviors of pristine $\mathrm{GO}$ are discussed including concentration, oxidation, $\mathrm{pH}$, and others. In terms of GO-composites, two aspects of their applications in lubricant additives and frictional pairs are introduced. Finally, several practical application cases of GO-based additions in water lubrication are included especially in metal working fluids and bio-lubricant. The challenges and outlook of GO-based materials in water lubrication are also analyzed. 


\section{Synthesis, structure, and lubrication mechanism of GO}

\subsection{The synthesis and structure of GO}

GO is mostly synthesized by graphite oxidation method, which generally goes through two steps: the preparation of graphite oxide and the exfoliation progress. The earliest synthesis of graphite oxide is tracked back to Brodie [8] in 1859. The use of fuming nitric acid and potassium chlorate made the synthesis progress dangerous and inefficient. Subsequently, Staudenmaier et al. [9] utilized a mixture of concentrated sulfuric acid and nitric acid instead of fuming nitric acid improving the reaction yield and safety. Hummer and Offeman [10] took potassium permanganate as the oxidant and avoided concentrated nitric acid in synthesis laying the foundation of contemporary synthesis of GO. The modern synthesis methods of GO are mostly improved from Hummer's method but move toward greener, safer, and more economic directions. Marcano et al. [11] replaced concentrated sulfuric with a mixture of sulfuric acid and phosphoric acid mixture as the reaction solvent. This avoids the addition of nitrate and reduces pollution and risks. The resulting GO had higher oxidation degree and less defects. In Chen's method [12], the nitrate was avoided and the use of acid was reduced significantly exhibiting excellent environmental and economic value. A summary of synthetic methods of GO is shown in Table 2 and reveals the development.

The structure of GO has been described in the Hofmann model [21], Ruess model [22], Schole-Boehm model [23], Nakajima-Matsuo model [24], and Lerf-
Klinowski model (L-K model) [25] as shown in Fig. 1. $\mathrm{GO}$ is inclined to be considered as periodic crystals reflected in the first four structural models. With further research, the non-stoichiometric and amorphous characteristics of GO are revealed. Among these, the most widely accepted structural model is the L-K model. The details are as follows: the main body of GO is a periodically arranged benzene ring structure. Several carbon-carbon double bonds are replaced by carbon-oxygen bonds and plentiful oxygen-containing groups are formed during the oxidation progress. Hydroxyl and epoxy groups mainly distribute on the basal plane while carbonyl groups and carboxyl groups are located on the edges of GO. The arrangement of these groups on the GO is random and irregular.

\subsection{The lubrication mechanism of GO-based materials}

The basis of GO functioned as lubricants is to form effective tribofilms. In aqueous dispersion, GO-based materials can adsorb on the surface and form effective lubricant films for the coordination bond and hydrogen bond between oxygen-containing groups and contact surface. According to fluid lubrication theory, the lubricant film formed by water exhibits lower film thickness for the low viscosity and distributes little anti-fiction properties compared to GO lubrication films. In GO Pickering emulsions, in addition to the formation of GO lubrication films, the phase transition process plays an important role. The lubrication of emulsion mainly achieves by "plate-out" mechanism [26-28]. The oil-in-water emulsion transforms into a water-in-oil emulsion or demulsifies and forms a

Table 2 The summary of the synthetic methods of GO.

\begin{tabular}{|c|c|c|c|c|c|}
\hline Methods & Oxidants & $\begin{array}{l}\text { Infiltrating } \\
\text { medium }\end{array}$ & $\begin{array}{c}\text { Toxic } \\
\text { by-products }\end{array}$ & Innovation & Drawbacks \\
\hline Brodie's [8] & $\mathrm{KClO}_{3}$ & $\mathrm{HNO}_{3}$ & $\mathrm{ClO}_{2}$ etc. & $\begin{array}{c}\text { Pioneering work about synthesis } \\
\text { of GO }\end{array}$ & $\begin{array}{l}\text { Dangerous and polluted } \\
\text { synthesis }\end{array}$ \\
\hline Staudenmaier's [9] & $\mathrm{HNO}_{3}, \mathrm{KClO}_{3}$ & $\mathrm{H}_{2} \mathrm{SO}_{4}$ & $\mathrm{Cl}_{2}, \mathrm{ClO}_{2}$ & $\begin{array}{l}\text { The avoidance of fuming nitric acid } \\
\text { improved the reaction yield and safety. }\end{array}$ & $\begin{array}{l}\text { Long oxidation progress } \\
\text { and low oxidation efficacy }\end{array}$ \\
\hline Hummer's [10] & $\mathrm{NaNO}_{3}, \mathrm{KMnO}_{4}$ & $\mathrm{H}_{2} \mathrm{SO}_{4}$ & $\mathrm{NO}, \mathrm{NO}_{2}$ & $\begin{array}{l}\text { Introduce } \mathrm{KMnO}_{4} \text { as oxidants and } \\
\text { avoid using concentrated nitric acid }\end{array}$ & $\begin{array}{c}\text { The toxic by-products were } \\
\text { not avoided }\end{array}$ \\
\hline Marcano's [11] & $\mathrm{KMnO}_{4}$ & $\mathrm{H}_{2} \mathrm{SO}_{4}, \mathrm{H}_{3} \mathrm{PO}_{4}$ & - & Realizing greener and safer synthesis & $\begin{array}{l}\text { Uncontrollable oxidation } \\
\text { process }\end{array}$ \\
\hline Chen's [12] & $\mathrm{KMnO}_{4}$ & $\mathrm{H}_{2} \mathrm{SO}_{4}$ & - & $\begin{array}{l}\text { Less waste and usage of raw materials, } \\
\text { simplified synthesis progress }\end{array}$ & Low oxidation efficacy \\
\hline
\end{tabular}


(a)

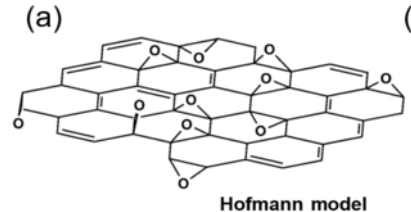

(c)

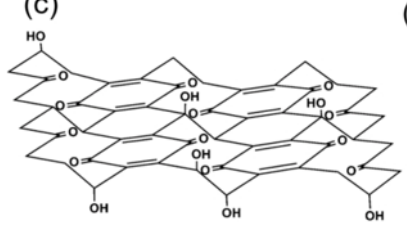

(e)

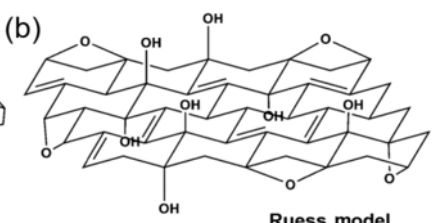

(d)
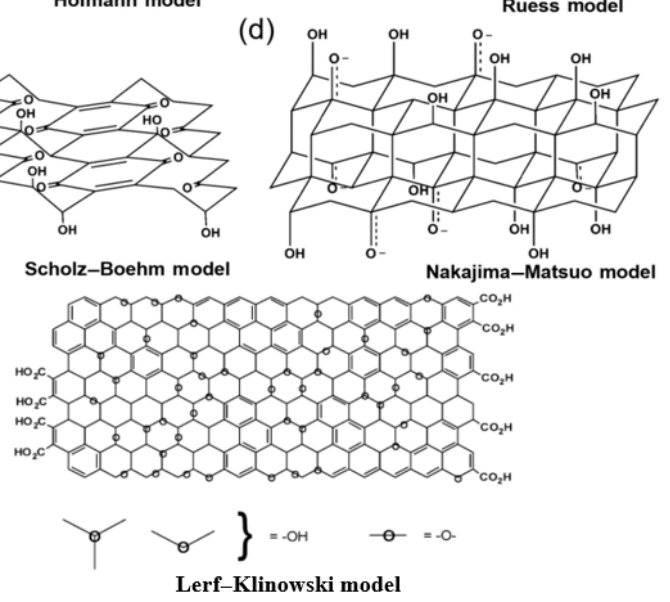

Fig. 1 Several proposed structural models of GO.

continuous oil phase on the surface of the frictional pairs, influenced by the high pressure and temperature during friction progress. Besides, the adsorption of GO on the contact surfaces will bring out the oil phase and reduce friction jointly.

The main theories reported to explain the enhancement of GO-based materials include the protecting and self-repairing mechanism [29], and interlayer lubrication mechanism [30, 31]. The GO has the similar mechanical properties as graphene with highest intrinsic strength (130 GPa) and outstanding thermal conductivity $\left(5000 \mathrm{~W} \cdot \mathrm{m}^{-1} \cdot \mathrm{K}^{-1}\right)$ [32]. Therefore, the tribofilms formed by GO protect contact areas decrease the risks of breakage obviously. GO films also transferred the energy quickly avoiding the thermal deformation caused by excessive heat concentration on contact areas. Besides, GO filling into the wear tracks, decreases the roughness of frictional pairs and avoids further destruction [33]. Interlayer slip is one of the main reasons for the excellent lubricating properties of 2D layered structural materials. The layers of graphene are mainly linked by Van der Waals' forces. The shear occurs easily in the direction parallel to the layers obviously decreasing the friction. A deeper study found that the interlayer sliding friction is small when graphene sheets are stacked in an incommensurate state [34-36]. However, the reports proved that the interlayer slip resistance may be increased due to additional hydrogen bond between GO layers compared to grapheme [37]. Besides, when GO is modified by the rigid spherical and quasispherical nanoparticles [38, 39], it can function as bearings and transform the sliding friction into rolling friction partly.

The structure of GO also has obvious effect on its tribology behavior. With the assistance of molecular dynamic simulation, the antifriction progress of GO is revealed in microscale. The detached and transferred hydroxyl groups, resulting from tribochemical reaction and the hydrogen transfer, aggravated the friction. It was found that the friction can be reduced by the conversion from GO to graphene during the tribology progress. The bond breaking related to the friction is associated with the transformation of epoxide groups during the wear of GO. Thus, the anti-wear properties might be enhanced by decreasing the ratios of epoxide groups [40]. Several points were also reported by Yuan et al.' s group [37]. The epoxy groups had the greatest influence on the structure and friction properties, followed by hydroxyl, carboxyl, and ketone groups. And less epoxy groups may be helpful for increasing the lubrication efficacy.

In fact, various mechanisms may take effect simultaneously making the mechanism complex during lubrication progress. The micro lubrication mechanism combined with the macroscopic tribology behaviors of $\mathrm{GO}$ needs more attention.

\section{Tribology behaviors of pristine GO in water lubrication}

The production of GO has been industrialized due to its low price and mature preparation technology. Abundant oxygen-containing functional groups make GO exhibit great dispersibility in polar solvent, providing great assistance to achieve efficient lubrication. GO additives improves the lubrication efficacy in aqueous dispersion significantly and even achieves superlubricity. The superlubricity reaches a nearly ideal contact state with no energy loss and its measurement of ultra-low dynamic COF (0.01-less) has approached the current test limit [41]. Especially, the superlubricity of GO appearing in macroscopic fluid lubrication provides new direction for water 
lubrication. In Ge et al.'s work [42], aqueous superlubricity in microscale was achieved by aqueous GO-ethanediol dispersion. The superlubricity state was stable at a concentration as low as $0.08 \%$ and a contact pressure as high as $111 \mathrm{MPa}$. The lubrication mechanism analysis proved that the superior anti-wear properties mainly originate from the thicker GO adsorbed film. The low shear stress between adjacent GO layers, low friction at the GO-ethanediol interface, and formation of hydrated GO-ethanediol networks jointly functioned outstanding anti-friction properties and achieved stable superlubricity. After that, Ge et al. [43] achieved robust macroscale liquid-superlubricity state with the combination of GO aqueous solution and ionic liquid under more severe conditions (contact pressure up to $600 \mathrm{MPa}$ ). In wearing-in period, the boundary layer formed by the ionic liquid contributed to superior antiwear properties. The mechanical properties and low shear stress among GO layers played major roles in superlubricity period.

The efficient water lubrication of GO is affected by many factors, including concentration, oxidation degree, $\mathrm{pH}$ value and others (Table 3 ). The relationship between GO structure and tribology behaviors influenced by these factors is analyzed as below.

\subsection{Influence of the concentration of GO}

The concentration of GO dominates the amount and distribution of GO at the frictional interface and is directly related to lubrication effect. Generally, the lubrication efficacy is positively correlated with concentration within a certain range. After exceeding a certain value, the COF will obviously increase with rising GO concentration.

Zhao et al. [44] set up several concentration gradients from 0.05 to $0.2 \mathrm{wt} \%$ and found that the optimal concentration was $0.15 \mathrm{wt} \%$ due to the uniform distribution of GO on the interface as shown by $2 \mathrm{D}$

Table 3 The summary of the tribological properties of pristine GO applied in water lubrication.

\begin{tabular}{|c|c|c|c|c|c|c|c|}
\hline $\begin{array}{l}\text { Influencing } \\
\text { factors }\end{array}$ & Variable range & Optimum & $\begin{array}{l}\text { Reduction in COF or wear } \\
\text { (verse pure water) }\end{array}$ & Test conditions & Frictional pairs & Test mode & Ref. \\
\hline \multirow{4}{*}{$\begin{array}{l}\text { Concen- } \\
\text { tration }\end{array}$} & $0.05-0.2 \mathrm{wt} \%$ & $0.15 \mathrm{wt} \%$ & $\begin{array}{c}\text { COF: } 39.2 \% \\
\text { (from } 0.378 \text { to } 0.23 \text { ) } \\
\text { Wear: } 64 \%\end{array}$ & $\begin{array}{c}\text { Load: } 2 \mathrm{~N} \\
\text { Velocity: } 0.2 \mathrm{~m} / \mathrm{s} \\
\text { Temperature: RT }\end{array}$ & $\begin{array}{l}\text { Balls and plates: } \\
304 \text { steel }\end{array}$ & $\begin{array}{l}\text { Ball on plate } \\
\text { rotation }\end{array}$ & [44] \\
\hline & $0.01-0.1 \mathrm{wt} \%$ & $0.1 \mathrm{wt} \%$ & $\begin{array}{c}\text { COF: } 79 \% \\
\text { (from } 0.56 \text { to } 0.12 \text { ) } \\
\text { Wear: } 68 \%\end{array}$ & $\begin{array}{c}\text { Load: } 5-20 \mathrm{~N} \\
\text { (1,420 MPa) } \\
\text { Velocity: } 0.005-0.1 \mathrm{~m} / \mathrm{s} \\
\text { Temperature: RT }\end{array}$ & $\begin{array}{l}\text { Balls and plates: } \\
304 \text { steel }\end{array}$ & $\begin{array}{l}\text { Ball on plate } \\
\text { reciprocation }\end{array}$ & {$[45]$} \\
\hline & $0-1.0 \mathrm{wt} \%$ & $0.5 \mathrm{wt} \%$ & $\begin{array}{c}\text { COF: } 77.5 \% \\
\text { (from } 0.169 \text { to } 0.038 \text { ) } \\
\text { Wear: } 90 \%\end{array}$ & $\begin{array}{c}\text { Load: } 3 \mathrm{~N}(312 \mathrm{MPa}) \\
\text { Velocity: } 0.08 \mathrm{~m} / \mathrm{s} \\
\text { Temperature: RT }\end{array}$ & $\begin{array}{c}\text { Balls: steel } \\
\text { Plates: AZ31Mg } \\
\text { alloy }\end{array}$ & $\begin{array}{l}\text { Ball on plate } \\
\text { reciprocation }\end{array}$ & {$[46]$} \\
\hline & $0-2 \mathrm{wt} \%$ & $1 \mathrm{wt} \%$ & $\begin{array}{c}\text { COF: } 57 \% \\
\text { (from } 0.14 \text { to } 0.06 \text { ) }\end{array}$ & $\begin{array}{c}\text { Load: } 10 \mathrm{~N} \\
\text { Velocity: } 0.02 \mathrm{~m} / \mathrm{s} \\
\text { Temperature: } 22^{\circ} \mathrm{C}\end{array}$ & $\begin{array}{c}\text { Balls: stainless steel } \\
\text { Plates: } \\
\text { diamond-like } \\
\text { carbon coated steel }\end{array}$ & $\begin{array}{l}\text { Ball on plate } \\
\text { reciprocation }\end{array}$ & {$[47]$} \\
\hline $\begin{array}{l}\text { Oxidation } \\
\text { degree }\end{array}$ & $\begin{array}{c}\text { Roc: } \\
52.48 \%-60.68 \%\end{array}$ & $\begin{array}{l}\text { Roc: } \\
60.68 \%\end{array}$ & $\begin{array}{c}\text { COF: } 46 \% \\
\text { (from } 0.378 \text { to } 0.204 \text { ) } \\
\text { Wear: } 60 \%\end{array}$ & $\begin{array}{c}\text { Load: } 2 \mathrm{~N} \\
\text { Velocity: } 0.02 \mathrm{~m} / \mathrm{s} \\
\text { Temperature: } 50^{\circ} \mathrm{C}\end{array}$ & $\begin{array}{l}\text { Balls and plates: } \\
304 \text { steel }\end{array}$ & $\begin{array}{l}\text { Ball on plate } \\
\text { rotation }\end{array}$ & [44] \\
\hline \multirow{3}{*}{$\mathrm{pH}$ value } & $\begin{array}{c}\text { pH: } 3.10,5.41, \\
6.62,8.80,9.70 \\
\text { (adjusted by } \mathrm{NaOH} \text { ) }\end{array}$ & pH: 3.1 & $\begin{array}{c}\text { COF: } 44.4 \% \\
\text { (from } 0.4 \text { to } 0.224 \text { ) } \\
\text { Wear: wear mark radius } \\
\text { reduced by } 17.1 \%\end{array}$ & $\begin{array}{c}\text { Load: } 20 \mathrm{~N} \\
\text { (689 MPa) } \\
\text { Velocity: } 0.05 \mathrm{~m} / \mathrm{s}\end{array}$ & $\begin{array}{c}\text { Balls: Cr alloy steel } \\
\text { Plates: } \\
304 \text { stainless steel }\end{array}$ & $\begin{array}{l}\text { Ball on three } \\
\text { plates }\end{array}$ & [48] \\
\hline & $\begin{array}{l}\mathrm{pH}: 3,5,7,9,10 \\
\text { (adjusted by } \mathrm{K}_{2} \mathrm{CO}_{3} \text { ) }\end{array}$ & pH: 3 & $\begin{array}{l}\text { COF: reached minimum } \\
\text { at } 0.05\end{array}$ & $\begin{array}{c}\text { Load: } 3 \mathrm{~N} \\
\text { Velocity: } 300 \mathrm{rpm}\end{array}$ & $\begin{array}{l}\text { Balls: tungsten } \\
\text { carbide } \\
\text { Plates: } 304 \\
\text { stainless steel }\end{array}$ & $\begin{array}{l}\text { Ball on plate } \\
\text { rotation }\end{array}$ & [49] \\
\hline & $\begin{array}{c}\mathrm{pH}: 2.8,5,7,8,9 \\
\quad \text { (adjusted by } \\
\text { triethanolamine) }\end{array}$ & pH: 9 & $\begin{array}{c}\text { COF: reached minimum } \\
\text { at } 0.0945 \\
\text { Wear: } P_{\mathrm{B}} 471 \mathrm{~N} ; \\
\text { minimum wear scars } \\
\text { diameter reached at } 616 \mu \mathrm{m}\end{array}$ & $\begin{array}{c}\text { Load: } 147 \mathrm{~N} \\
\text { Velocity: } 1,200 \mathrm{rpm} \\
\text { Temperature: } 25^{\circ} \mathrm{C}\end{array}$ & Balls: GCr15 & Four balls & [50] \\
\hline
\end{tabular}


Raman. The decreased COF and wear rate appeared to rebound when the concentration is greater than $0.15 \mathrm{wt} \%$. Singh et al. [45] studied the effect of test conditions based on the optimal concentration. They got an optimal concentration at $0.1 \mathrm{wt} \%$ where the COF decreased from 0.56 (pure water) to 0.12 with an attendant reduction in wear volume by $68 \%$. The lubrication efficacy would reduce under more demanding test conditions. Better circulation of GO aqueous solution enhances the formation of tribo-layer and lubricants squeezed out of the contact surface at high speed.

The diverse and optimal concentration was proved to not be strictly regulated but this depended on the application scenario and the preparation progress of GO. Xie et al. [46] compared the lubrication effect of graphene and GO in aqueous solution. The best lubrication response was at $0.5 \mathrm{wt} \%$ GO. At this optimal concentration, the COF and wear rate decreased $77.5 \%$ and $90 \%$, respectively, in GO aqueous solution, which is much higher than that in graphene nanofluids. Elomama et al. [47] studied the friction and wear performance of GO dispersions in water at diamond-like carbon vs. stainless steel contact. The COF decreased $57 \%$ compared to pure water when $1.0 \mathrm{wt} \%$ of GO and $10 \mathrm{~N}$ normal load were applied.

As the concentration gradually increases, the resulting lubricating film on the surface of the friction pairs becomes more uniform and denser. The corresponding concentration is considered optimal when COF reaches the lowest. However, GO will agglomerate on the surface and reduce the flatness of the frictional pairs when it exceeds the optimal value, causing abrasive wear and reducing the lubrication effect [51]. In fact, the concentration of GO as additives in water lubrication is rarely higher than $1 \mathrm{wt} \%$, otherwise the GO aqueous solution cannot maintain uniform dispersion for long-time storage and the aggregated GO on wear tracks leads to abrasive wear. The recommended concentration of GO is $0.1-0.5 \mathrm{wt} \%$ in water lubrication generally.

\subsection{Influence of the oxidation degree of GO}

GO can be obtained by different preparation methods and raw material ratios according to previous discussion. The productions have significant differences in structure, in which the degree of oxidation was a common index to measure and distinguish the various GO. The higher oxidation degree of GO generally means more amounts of oxygen containing functional groups, larger layer distances, and more serious structural defect. The adsorption on interface and electrochemical properties of GO will be affected by oxidation degree [52].

Zhao et al. [44] prepared GO with different oxidation degree by changing the ratio of graphite, potassium permanganate, and concentrated sulfuric acid according to improved Hummer's method. The ratio of oxidized C atoms (Roc) was calculated as the index of oxidation degree of $\mathrm{GO}$, by the integral area ratio of fitting peaks in C XPS spectrum. They compared the lubrication property of these GO aqueous solutions under same concentration. The results proved that the higher oxidation degree GO behaved better tribology properties (Fig. 2). The COF and wear rate decreased by up to $64 \%$ and $46 \%$, respectively. The oxidation degree of GO reflected the amounts of oxygencontaining functional groups, which decided the hydrophilicity and adsorption of GO on the friction pairs. GO with higher oxidation degree means the more adsorption sites on frictional pairs. From a macro perspective, it resulted in better water dispersibility, and faster and firmer adsorption on the contact surface, corresponding to lower COF mostly.

\subsection{Influence of the $\mathrm{pH}$ environment of GO}

As abundant oxygen-containing functional groups are significantly affected by the protonation effect, the structure of GO is very sensitive to $\mathrm{pH}$ value. Reflected in the macro nature, the performance of GO in dispersion, lateral size, wettability, interfacial properties and so on, the factors influencing the lubrication performance of GO, is greatly affected by $\mathrm{pH}$ environment.

Previous studies proved that the oxygen-containing functional groups of GO, especially the carboxyl groups, behave as distinct hydrophilia at various $\mathrm{pH}$ environments. The alkaline environment is more conducive to the dispersion of GO in water. The electrostatic repulsion among GO sheets, originating from the deprotonation of functional groups, can decrease the aggregation of GO and exhibit uniform 

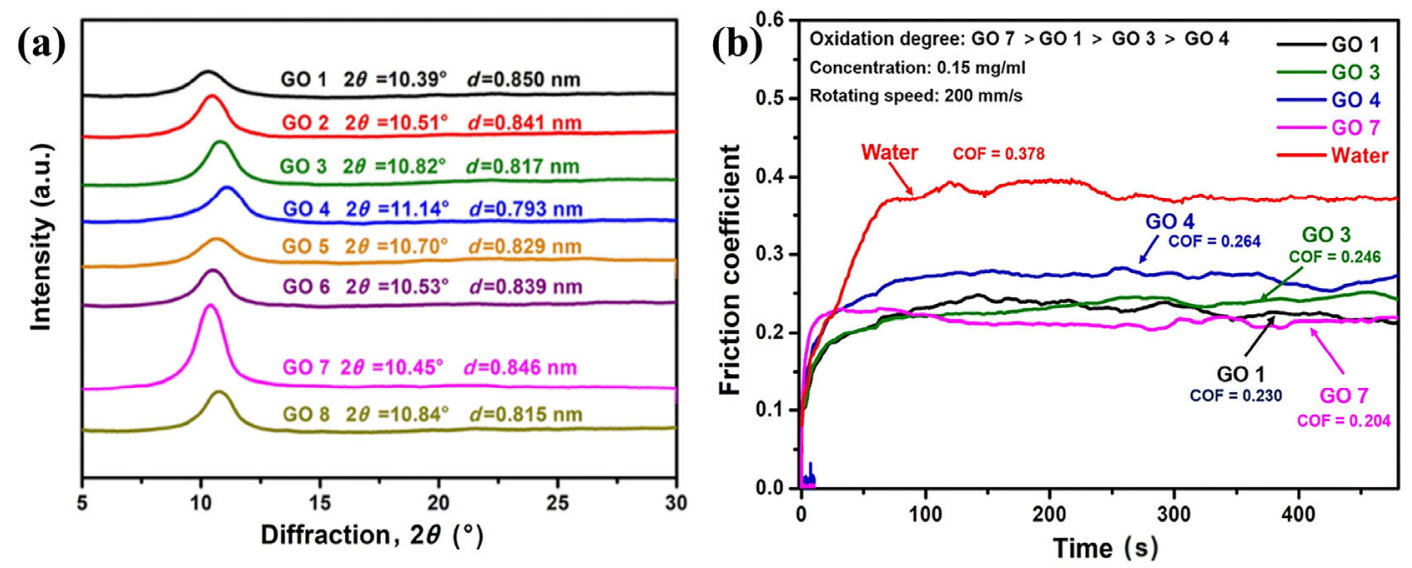

(c)

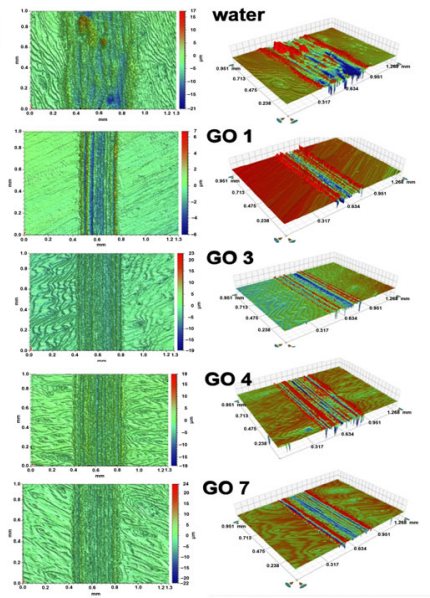

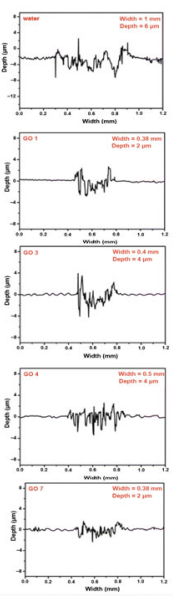

(d)

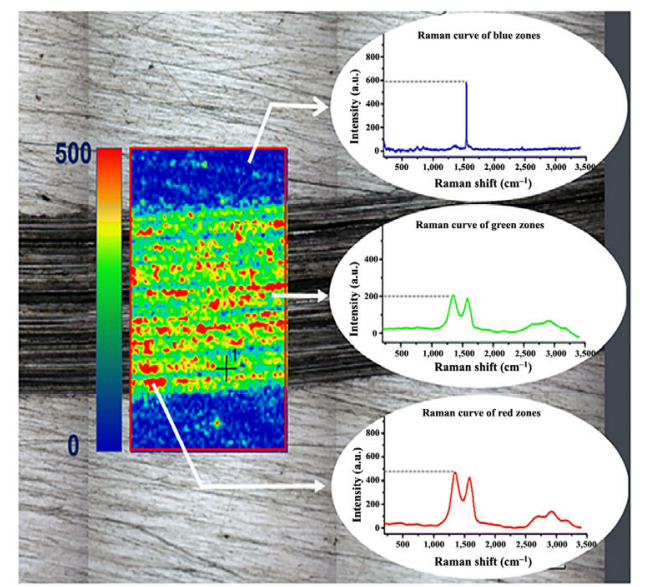

Fig. 2 (a) The XRD spectra of GOs. (b) The fictional curves of GO and (c) surface topography of the wear scar lubricated by GOs suspension. (d) The full-area Raman test of the wear track on the plate. Reproduced with permission from Ref. [44], (C) Springer Nature, 2019.

dispersion in lubricant liquid, which was proved by Zeta potential test [53]. The evenly distributed GO on frictional pairs is easier to achieve efficient lubrication. The alkaline GO aqueous dispersion also provides higher upper limit of concentration, which is involved with the lubrication effect closely.

Research by $\mathrm{Wu}$ et al. [54] proved that the lateral size of GO was also relevant to the $\mathrm{pH}$ value. Their team revealed that the small size sheets tended to be acidic or basic due to the protonation of carboxyl groups in acidic environment and removal of carboxyl groups in basic environment. However, larger GO nanosheets tend to exist in neutral and alkalescent environments. The influence of lateral size brought by $\mathrm{pH}$ may cause different tribology behaviors. GO with lager size in acidic environment exhibits structural integrity, flexible morphology and better mechanical properties. But GO with smaller size in alkalescent environments, is more probable to enter the narrow contact areas and fill into the small size of wear scars under certain special conditions.

Furthermore, the $\mathrm{pH}$ environment significantly affects the interfacial tension of GO influencing the stability and types of emulsion when GO acted as a Pickering particle. He et al. [55] reported that GO had better interfacial activity and formed more stable oil-in-water Pickering emulsion systems at low $\mathrm{pH}$ value (Fig. 3). The droplets of emulsion get smaller and more uniform with a decrease in $\mathrm{pH}$ value. The stable emulsion system has great significance for the lubrication property in long term.

He et al. [48] synthesized GO aqueous dispersion with various $\mathrm{pH}$ value. The GO suspension with $\mathrm{pH}$ of 3.10 behaved best anti-friction property. The COF and wear mark radius decreased by $44.4 \%$ and $17.1 \%$ versus water with same $\mathrm{pH}$ value. The better lubrication property may benefit from the structural integrity, large lateral surface area, and flexible morphology of 

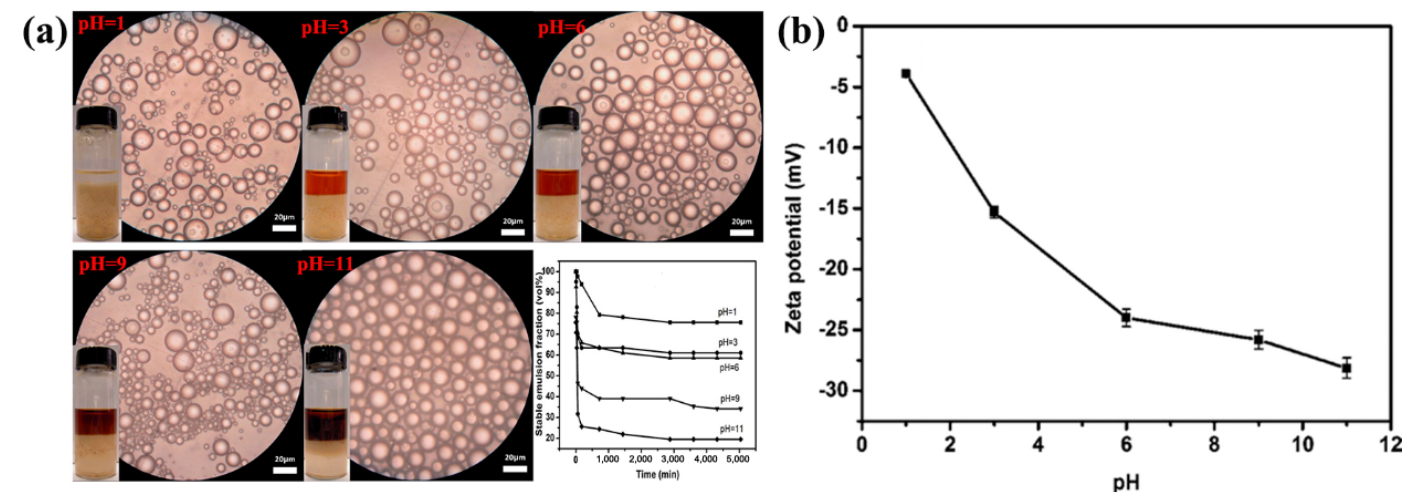

Fig. 3 (a) The optical micrographs and photographs $72 \mathrm{~h}$ after preparation of Pickering emulsions stabilized by $\mathrm{GO}$ at different $\mathrm{pH}$ values and volume fraction of the residual emulsion as a function of time at different $\mathrm{pH}$ values. (b) The change of the Zeta potentials of $0.1 \mathrm{wt} \%$ GO dispersed in water at different pH values. Reproduced with permission from Ref. [55], (c) American Chemical Society, 2016.

GO sheets under acidic environment. Alias et al. [49] prepared $\mathrm{GO}$ aqueous dispersion with different $\mathrm{pH}$ value taking $\mathrm{K}_{2} \mathrm{CO}_{3}$ as $\mathrm{pH}$ modifier. They found that the GO solution with lower $\mathrm{pH}$ exhibited better lubrication effect. The COF could reach 0.05 at least under $\mathrm{pH}=3$. The lubrication effect had a nearly linear decline with increasing $\mathrm{pH}$ value. The GO solution at $\mathrm{pH}=10$ did not show any lubricant properties. However, Meng's research [50] found that alkaline GO suspension $(\mathrm{pH}=9)$ adjusted by triethanolamine behaved better lubrication performance on the strip surfaces during cold rolling. The COF, wear scar diameter, and the minimum rolling thicknesses of the rolled strips in GO aqueous suspension ( $\mathrm{pH}=9$ ) decreased by $28.6 \%$, $21.6 \%$, and $10.84 \%$, respectively, and the last nonseizure load decreased by $20 \%$, versus $\mathrm{GO}$ aqueous suspension with $\mathrm{pH}$ of 2.8. They proposed that the alkalescent GO aqueous suspension had better dispersion and smaller size. The GO sheets entered the contact area between the roll and strip easily, forming thin and efficient adsorption film.

In fact, the $\mathrm{pH}$ value generated great effect on the lubrication property. The acidic GO aqueous dispersion is beneficial to behave better interfacial activity and construct stable Pickering emulsion. The superior wettability of GO in acidic environment, owing to the strong polarity and large lateral surface, produce strong adhesion on the frictional pairs and then decrease the friction loss by avoiding direct contact. Besides, GO tends to perform lager lateral size and better integrity in acidic environment, generating GO tribofilm with better anti-friction properties. On the contrary, the alkaline environment is more suitable to construct uniform GO suspension with more controllable concentration. Therefore, the actual lubrication performance needs to consider the detailed operating condition. The selection of $\mathrm{pH}$ in actual production is sub-optimal. Other than the tribology performance, other impacts such as corrosion and safety, also need consideration.

\subsection{Influence of the other factors of GO}

\subsubsection{The lateral size of $G O$}

The lateral size of GO exhibited significant effect on lubrication properties. Relevant research proved that lager size of GO behaved better mechanical properties with more tight and perfect structure. Considering the carboxyl groups mainly distributed on the edge of GO, the ratios of carboxyl groups increase with the decrease of lateral size of GO, resulting in better aqueous dispersibility relatively [53]. The lateral size of GO can be controlled by the centrifugation [53,56], $\mathrm{pH}$ value [54], and ultrasonic treatment with different time $[57,58]$.

However, few works were reported to discuss the influence of lateral size of GO on tribology properties specifically. According to above analysis, GO with different lateral size may be complicated. The tribofilm formed by lager lateral size of GO may behave better antiwear properties for the firmer GO adsorption films. It is favorable for GO with smaller lateral size to enter the contact areas and function as additives. The exact relationship between lateral size and tribology properties needs more in-deep exploration in future. 


\subsubsection{The thickness of GO}

The physical properties of graphene material such as electronics, mechanics, and lubrication are closely related to thickness. The thickness is approximately equal to the product of the number of layers and interlayer thickness. Research about the relationship of friction and thickness mainly focuses on nanosolid lubrication in microscale by AFM [59-62] and molecular dynamic simulation [63-65]. Mostly, the friction had negative correlation with sheet thickness in graphene, for absence of interlayer lubrication and poor carrying capacity.

Some research reveals the microscale dependence of sheet thickness of GO on frictional properties is different from graphene. Kwon et al. [66] reported a phenomenon that the friction between GO sheet and $\mathrm{SiO}_{2}$ substrate behaved as no correlation with the number of layers of GO. Lee et al. [67] found the friction is heterogeneous on the monolayer GO sheet (Fig. 4). The low friction and high friction corresponded to the $\mathrm{sp}^{2}$ - and $\mathrm{sp}^{3}$-carbon-dominant domains, respectively.

Owning to the aggregation of GO sheets, the precise control of thickness of GO is hard to achieve in aqueous dispersion. The existing research mainly explores the tribology behaviors of monolayer GO [68, 69]. The analysis about the relationship between thickness of GO and lubrication efficacy is rarely reported. The thickness of GO affects the tribology properties greatly, such as the load capacity, the formation of tribofilms, and interlayer slide. The combination between macroscopic tribology measurement and in-deep mechanism analysis is necessary to reveal the influence of GO thickness in water lubrication.

\section{GO composite applied as lubricant additives in water lubrication}

Various substances are doped into GO to improve the tribology property and endow GO-based lubricant additives with more functions. The GO composite not only maintains the excellent physical properties of GO but also is strengthened in the performance of lubrication, dispersion, and interfacial activity. The synergy effect of each competent of composites may generate several unexpected features. Moreover, the GO composites can also respond specifically to the different application scenarios. As a result, it is a convenient and efficient way to take GO composites as lubricant additives. According to the categories of the dopant, the GO-based composites as lubricant additives are classified into GO-inorganic composites and GO-organic composites (Table 4). (a)

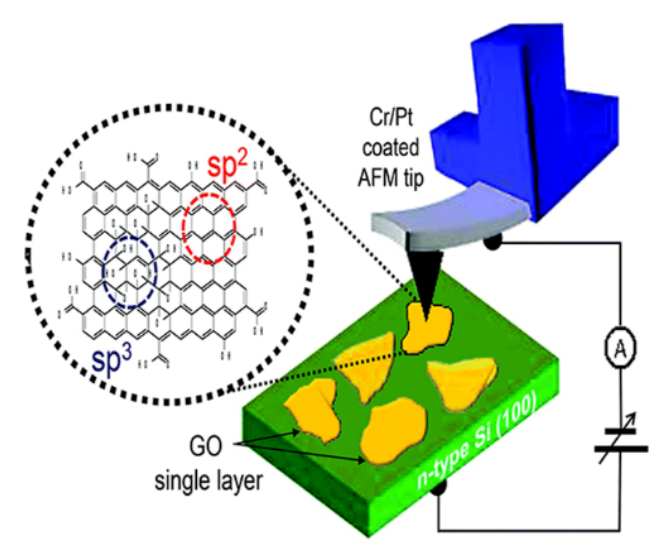

(b)

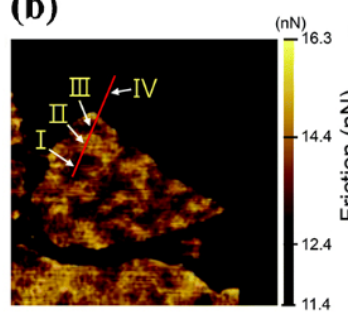

(c)

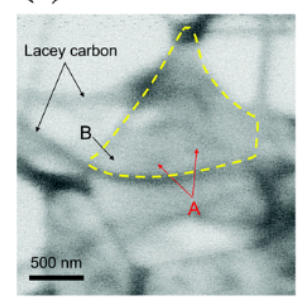

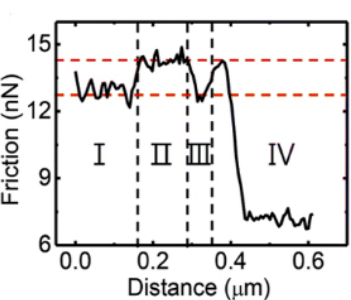

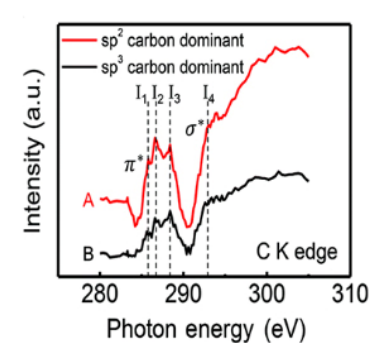

Fig. 4 (a) Scheme for probing the electrical characterization of single-layer GO on $\mathrm{SiO}_{2} / \mathrm{n}$-Si. (b) Friction force of a single-layer GO on $\mathrm{SiO}_{2} / \mathrm{n}$-Si and cross profiles of friction along the red lines. (c) STXM chemical mapping of the GO sheet on lacey carbon and $\mathrm{C}$ K-edge NEXAFS spectra of A regions ( $\mathrm{sp}^{2}$-carbon dominant) and $\mathrm{B}$ ( $\mathrm{sp}^{3}$-carbon dominant) regions. Reproduced with permission from Ref. [67], (C) Royal Society of Chemistry, 2016. 
Table 4 The summary of GO based composites applied as lubricant additives in water lubrication.

\begin{tabular}{|c|c|c|c|c|c|c|c|c|}
\hline & Composites & Optimum & Tribology property & $\begin{array}{l}\text { Lubrication } \\
\text { system }\end{array}$ & Frictional pairs & Test conditions & Test mode & Ref. \\
\hline \multirow{5}{*}{$\begin{array}{l}\text { GO- } \\
\text { oxides }\end{array}$} & $\begin{array}{l}\mathrm{GO} / \mathrm{APTES} \\
\text { modified } \mathrm{SiO}_{2}\end{array}$ & $\begin{array}{l}\text { Concentration: } \\
0.2 \mathrm{wt} \%\end{array}$ & $\begin{array}{l}\text { COF: }-0.07 \text {; almost } 50 \% \\
\text { reduction in wear volume }\end{array}$ & $\begin{array}{l}\text { Aqueous } \\
\text { solution }\end{array}$ & $\begin{array}{c}\text { Balls: GCr15 } \\
\text { steel; Plates: } \\
\text { diamond-like } \\
\text { carbon coated } 304 \\
\text { stainless steel }\end{array}$ & $\begin{array}{c}\text { Load: } 10 \mathrm{~N} \\
(1,440 \mathrm{MPa}) \\
\text { Velocity: } 0.025 \mathrm{~m} / \mathrm{s} \\
\text { Temperature: } \\
30 \pm 5^{\circ} \mathrm{C}\end{array}$ & $\begin{array}{l}\text { Ball on } \\
\text { plate re- } \\
\text { ciprocation }\end{array}$ & {$[70]$} \\
\hline & $\mathrm{GO} / \mathrm{SiO}_{2}$ & $\begin{array}{l}\text { Concentration: } \\
0.16 \mathrm{wt} \%\end{array}$ & $\begin{array}{l}50 \% \text { reduction in COF } \\
\text { (from } 0.52 \text { to } 0.26) ; \\
38 \% \text { reduction in Ra of } \\
\quad \text { lapped surface }\end{array}$ & $\begin{array}{l}\text { Mixed } \\
\text { aqueous } \\
\text { solution } \\
\left(\mathrm{H}_{2} \mathrm{O}\right. \\
70 \mathrm{wt} \%)\end{array}$ & $\begin{array}{l}\text { Blocks: Cr alloy } \\
\text { steel; Rings: } 304 \\
\text { stainless steel }\end{array}$ & $\begin{array}{l}\text { Load: } 20 \mathrm{~N} \\
\text { Velocity: } 0.02 \mathrm{~m} / \mathrm{s} \\
\text { Temperature: } \mathrm{RT}\end{array}$ & $\begin{array}{l}\text { Block on } \\
\text { ring }\end{array}$ & [71] \\
\hline & $\mathrm{GO} / \mathrm{SiO}_{2}$ & $\begin{array}{l}\text { Ratio: GO: } \\
\mathrm{SiO}_{2}=0.02 \mathrm{wt} \%: \\
0.50 \mathrm{wt} \%\end{array}$ & $\begin{array}{l}\text { Almost } 30 \% \text { reduction in } \\
\text { COF (from } 0.11 \text { to } 0.07) \text {; } \\
\text { almost } 15 \% \text { reduction in } \\
\text { worn scar diameter (WSD) }\end{array}$ & $\begin{array}{l}\text { PEG } \\
\text { aqueous } \\
\text { solution }\end{array}$ & $\begin{array}{l}\text { Balls: } 52100 \\
\text { steel }\end{array}$ & $\begin{array}{c}\text { Load: } 294 \mathrm{~N} \\
\text { Velocity: } \\
\text { 1,200 rpm } \\
\text { Temperature: } 25^{\circ} \mathrm{C}\end{array}$ & Four balls & {$[72]$} \\
\hline & $\mathrm{GO} / \mathrm{Al}_{2} \mathrm{O}_{3}$ & $\begin{array}{c}\text { Concentration: } \\
0.06 \mathrm{wt} \% \\
\text { Ratio: } \mathrm{GO} / \\
\mathrm{Al}_{2} \mathrm{O}_{3}=1: 1\end{array}$ & $\begin{array}{l}66 \% \text { reduction in COF } \\
\text { (from } 0.53 \text { to } 0.19) ; \\
64 \% \text { improvement in } \\
\text { surface finish }\end{array}$ & $\begin{array}{l}\text { Aqueous } \\
\text { solution }\end{array}$ & $\begin{array}{l}\text { Blocks: } 304 \\
\text { stainless steel; } \\
\text { Rings: } 52100 \\
\text { chrome steel }\end{array}$ & $\begin{array}{l}\text { Load: } 10-20 \mathrm{~N} \\
\text { Velocity: } 0.01 \mathrm{~m} / \mathrm{s} \\
\text { Temperature: } \\
20-25^{\circ} \mathrm{C}\end{array}$ & $\begin{array}{l}\text { Block on } \\
\text { ring }\end{array}$ & [39] \\
\hline & $\mathrm{GO} / \mathrm{TiO}_{2}$ & $\begin{array}{l}\text { Concentration: } \\
0.5 \mathrm{wt} \%\end{array}$ & $\begin{array}{l}12 \% \text { improvement in } P_{\mathrm{B}} \\
\text { value; COF: }-0.05 ; \\
23.6 \% \text { reduction in WSD }\end{array}$ & $\begin{array}{c}\text { Mixed } \\
\text { aqueous } \\
\text { solution } \\
\left(\mathrm{H}_{2} \mathrm{O}\right. \\
97.7 \mathrm{wt} \%)\end{array}$ & $\begin{array}{l}\text { Balls: GGr15 } \\
\text { standard }\end{array}$ & $\begin{array}{c}\text { Load: } 392 \mathrm{~N} \\
\text { Velocity: } \\
\text { 1,200 rpm } \\
\text { Temperature: } 20^{\circ} \mathrm{C}\end{array}$ & Four balls & [38] \\
\hline \multirow{3}{*}{$\begin{array}{l}\text { GO- } \\
\text { carbon- } \\
\text { aceous }\end{array}$} & $\begin{array}{l}\text { GO/nano- } \\
\text { diamond }\end{array}$ & $\begin{array}{l}\text { Ratio: GO: } \\
\text { nano-diamond= } \\
0.1 \mathrm{wt} \%: \\
0.5 \mathrm{wt} \%\end{array}$ & COF: -0.03 & $\begin{array}{l}\text { Aqueous } \\
\text { solution }\end{array}$ & $\begin{array}{c}\text { Balls: } \mathrm{Si}_{3} \mathrm{~N}_{4} \\
\text { Plates: } \mathrm{Si} \text { wafers }\end{array}$ & $\begin{array}{c}\text { Load: } 0.005-0.08 \mathrm{~N} \\
(160-400 \mathrm{MPa}) \\
\text { Velocity: } \\
0.0004 \mathrm{~m} / \mathrm{s} \\
\text { Temperature: } 25^{\circ} \mathrm{C}\end{array}$ & $\begin{array}{c}\text { Ball on } \\
\text { plate re- } \\
\text { ciprocation }\end{array}$ & {$[73]$} \\
\hline & $\begin{array}{l}\mathrm{GO} / \mathrm{MWCNT} \\
\text { s-COOH }\end{array}$ & $\begin{array}{c}\text { Concentration: } \\
0.7 \text { wt } \% \text {; Ratio: } \\
\text { GO: MWCNTs- } \\
\text { COOH =3:1 }\end{array}$ & $\begin{array}{l}\text { The COF and wear } \\
\text { volume reached lowest. }\end{array}$ & $\begin{array}{l}\text { Aqueous } \\
\text { solution }\end{array}$ & $\begin{array}{l}\text { Balls: stainless } \\
\text { steel; Plates: } \\
\text { GCr15 bearing } \\
\text { steel }\end{array}$ & $\begin{array}{c}\text { Load: } 10 \mathrm{~N} \\
\text { Velocity: } \\
0.0523 \mathrm{~m} / \mathrm{s} \\
\text { Temperature: RT }\end{array}$ & $\begin{array}{l}\text { Ball on } \\
\text { plate re- } \\
\text { ciprocation }\end{array}$ & [29] \\
\hline & $\mathrm{g}-\mathrm{C}_{3} \mathrm{~N}_{4} / \mathrm{GO}$ & $\begin{array}{l}\text { Concentration: } \\
0.06 \mathrm{wt} \% \\
\text { Ratio: } \\
\mathrm{g}_{-} \mathrm{C}_{3} \mathrm{~N}_{4}: \mathrm{GO}=1: 1\end{array}$ & $\begin{array}{l}37 \% \text { reduction in COF } \\
\text { (from } 0.39 \text { to } 0.25) ; \\
19.6 \% \text { reduction in WSD }\end{array}$ & $\begin{array}{l}\text { Aqueous } \\
\text { solution }\end{array}$ & $\begin{array}{l}\text { Balls: } 52100 \mathrm{Cr} \\
\text { Plates: } 304 \\
\text { stainless steel }\end{array}$ & $\begin{array}{c}\text { Load: } 10-35 \mathrm{~N} \\
(645-981 \mathrm{MPa}) \\
\text { Velocity: } 0.0025- \\
0.0125 \mathrm{~m} / \mathrm{s} \\
\text { Temperature: } 25^{\circ} \mathrm{C}\end{array}$ & $\begin{array}{l}\text { Ball on } \\
\text { plate re- } \\
\text { ciprocation }\end{array}$ & [74] \\
\hline \multirow{5}{*}{$\begin{array}{l}\text { GO- } \\
\text { organics }\end{array}$} & TTAB/GO & $\begin{array}{l}\text { Concentration: } \\
0.2 \mathrm{wt} \%\end{array}$ & $\begin{array}{l}18 \% \text { reduction in } \mathrm{COF} \\
48 \% \text { reduction in wear } \\
\text { volume }\end{array}$ & $\begin{array}{l}\text { Oil in } \\
\text { water } \\
\text { emulsion }\end{array}$ & $\begin{array}{l}\text { Ball and rings: } \\
52100 \text { bearing } \\
\text { steel }\end{array}$ & $\begin{array}{c}\text { Load: } 0.5 \mathrm{~N}(130 \\
\mathrm{MPa}) \\
\text { Velocity: } 0.02- \\
0.2 \mathrm{~m} / \mathrm{s} \\
\text { Temperature: RT }\end{array}$ & $\begin{array}{l}\text { Balls on } \\
\text { ring }\end{array}$ & [75] \\
\hline & $\begin{array}{l}\text { Triethano- } \\
\text { lamine/GO }\end{array}$ & $\begin{array}{l}\text { Concentration: } \\
0.3 \mathrm{wt} \%\end{array}$ & $\begin{array}{l}21.9 \% \text { reduction in } \mathrm{COF} \\
\text { (from } 0.20 \text { to } 0.156) ; \\
6.2 \% \text { reduction in WSD } \\
\text { (compared to GO } \\
\text { dispersion) }\end{array}$ & $\begin{array}{l}\text { Aqueous } \\
\text { solution }\end{array}$ & Balls: GCr15 & $\begin{array}{l}\text { Load: } 98 \mathrm{~N} \\
\text { Velocity: } \\
\text { 1,200 rpm } \\
\text { Temperature: } 20^{\circ} \mathrm{C}\end{array}$ & Four balls & {$[76]$} \\
\hline & $\begin{array}{l}\text { n-Octylamine/ } \\
\text { GO }\end{array}$ & $\begin{array}{l}\text { Concentration: } \\
0.01 \mathrm{wt} \%\end{array}$ & $\begin{array}{l}\text { basal plane } \\
\text { functionalized GO } \\
\text { (b-GO) behaved } \\
\text { lower COF }\end{array}$ & $\begin{array}{l}\text { Oil in } \\
\text { water } \\
\text { emulsion }\end{array}$ & $\begin{array}{c}\text { Balls and plates: } \\
304 \text { stainless } \\
\text { steel }\end{array}$ & $\begin{array}{c}\text { Load: } 2 \mathrm{~N}(500 \\
\mathrm{MPa}) \\
\text { Velocity: } 30- \\
\text { 200 rpm } \\
\text { Temperature: RT }\end{array}$ & $\begin{array}{l}\text { Ball on } \\
\text { plate } \\
\text { rotation }\end{array}$ & [77] \\
\hline & $\begin{array}{l}\text { Alkylamines/ } \\
\text { GO }\end{array}$ & $\begin{array}{l}\text { Concentration: } \\
0.01 \mathrm{wt} \%\end{array}$ & $\begin{array}{c}\text { Branch-chain modulated } \\
\text { GO (GO-4) reveals } \\
\text { lower friction. } \\
304 \text { stainless steel vs } \\
\text { UHMWPE had lowest } \\
\text { wear volume. }\end{array}$ & $\begin{array}{l}\text { Oil in } \\
\text { water } \\
\text { emulsion }\end{array}$ & $\begin{array}{l}\text { Balls: GCr15 } \\
\text { bearing steel; } \\
\text { Plates: } 304 \\
\text { stainless, } \\
\text { UHMWPE, etc. }\end{array}$ & $\begin{array}{c}\text { Load: } 2 \mathrm{~N} \\
\text { Velocity: } 0.08- \\
0.4 \mathrm{~m} / \mathrm{s} \\
\text { Temperature: RT }\end{array}$ & $\begin{array}{l}\text { Ball on } \\
\text { plate } \\
\text { rotation }\end{array}$ & [78] \\
\hline & $\begin{array}{l}\text { n-Octylamine/ } \\
\text { GO }\end{array}$ & $\begin{array}{l}\text { Concentration: } \\
0.01 \mathrm{wt} \%\end{array}$ & $\begin{array}{l}\text { GO with less intro- } \\
\text { ductions behaved better } \\
\text { lubrication effect. }\end{array}$ & $\begin{array}{l}\text { Oil in } \\
\text { water } \\
\text { emulsion }\end{array}$ & $\begin{array}{l}\text { Balls: GCr15 } \\
\text { bearing steel; } \\
\text { Plates: } 304 \\
\text { stainless }\end{array}$ & $\begin{array}{c}\text { Load: } 2 \mathrm{~N}(400 \\
\mathrm{MPa}) \\
\text { Velocity: } 0.08- \\
0.4 \mathrm{~m} / \mathrm{s} \\
\text { Temperature: RT }\end{array}$ & $\begin{array}{l}\text { Ball on } \\
\text { plate } \\
\text { rotation }\end{array}$ & [79] \\
\hline
\end{tabular}




\subsection{GO-inorganic composite}

The application of inorganic nanoparticles in water lubrication has been widely studied. The nanoparticles used as lubricants involve all categories of inorganics such as various oxides, carbonaceous nanoparticles, and others. In addition to superior antifriction and antiwear properties, inorganic nanoparticles present excellent adsorption on tribo-films, surface self-repairing functions, and heat transfer characteristics [80-82]. However, some limitations such as poor dispersibility restrict their utility. Nanoparticles in the lubricant fluid agglomerate easily due to van der Waals forces; thus, the stability of nanolubricating fluid is difficult to maintain [83]. The poor stability also reduces the antifriction and antiwear efficacy of inorganics nanolubricating fluid.

The combination with hydrophilic GO can effectively improve the stability of nanolubricating fluid via steric hindrance and electrostatic effects. Considering the potential of GO in lubrication, it is expecting to synthesize and apply GO-based inorganic composites into water lubrication. The synergistic friction-reducing and antiwear characteristics of each component are also worth study. Accordingly, inorganic particles combined with GO are introduced by oxides and carbonaceous inorganic nanoparticles.

\subsubsection{GO-inorganic oxide composite}

Oxides are the most common and richest sort of inorganics. Hence, their abundant sources and cost advantages make oxides ideal fortifiers. Oxides have advantages in terms of low density, low melting point, low phase transition temperature, and large surface area, which are important factors for lubrication. However, the obvious aggregation oxide particles impede effective exertion in lubrication. Therefore, the outstanding synergy effect of GO and inorganic oxides in lubrication is expecting. The GO-inorganic oxide composites include GO-nonmetal oxides and GO-metal oxides.

Nonmetal oxides

$\mathrm{SiO}_{2}$ is the main nonmetal oxide additives in lubrication. It offers eco-friendliness, good availability, and superior tribological performance. The superior lubrication effect of $\mathrm{SiO}_{2}$ is mainly due to protective films formed via the adsorption or interaction of the wear surface, as well as the dynamic balanced filling effect to the grooves during sliding. Due to its high hardness, the GO- $\mathrm{SiO}_{2}$ composites also have great improvements in bearing capacity.

$\mathrm{SiO}_{2}$ has a long history as a lubricant, and the application of $\mathrm{GO}-\mathrm{SiO}_{2}$ composites in water lubrication is reported recently. Guo et al. [70] synthesized a novel nanomaterial combining $\mathrm{GO}$ with 3-aminopropyltriethoxysilane (APTES)-modified $\mathrm{SiO}_{2}$ (Fig. 5). The tribology test proved that the average COF of the steady state for the concentration of $0.20 \mathrm{wt} \%$ was the lowest, while the COF for the concentration of $0.50 \mathrm{wt} \%$ was the most stable. In terms of antiwear property, the wear rate maintained a minimum when the concentration reached $0.07 \mathrm{wt} \%$. Huang et al. [71] prepared $\mathrm{GO} / \mathrm{SiO}_{2}$ via high-intensity ultrasonication method and used it in an efficient water-based grinding fluid. The aggregation of the $\mathrm{SiO}_{2}$ particles and restacking of the GO sheet in water were effectively alleviated. There were $50 \%$ and $38 \%$ reduction in $\mathrm{COF}$ and $\mathrm{Ra}$ of lapped surface, respectively, at a concentration of $0.16 \mathrm{wt} \%$. The superior performance was attributed to the tribofilm that consists of deposited carbon and $\mathrm{SiO}_{2}$. In the tribofilm, $\mathrm{GO}$ resisted the sheer and friction, and the $\mathrm{SiO}_{2}$ acted as polishing medium. Lv et al. [72] utilized $\mathrm{GO} / \mathrm{SiO}_{2}$ water-based lubricant as cutting fluids rather than vegetable oil and applied the minimum quantity lubrication. The $\mathrm{GO} / \mathrm{SiO}_{2}$ composite with different component ratios was prepared via ultrasonic mixing and stabilized via lauryl sodium sulfate surfactant. The COF and wear scar diameter were the lowest when the composites consisted of $0.02 \mathrm{wt} \% \mathrm{SiO}_{2}$ and $0.5 \mathrm{wt} \% \mathrm{GO}$.

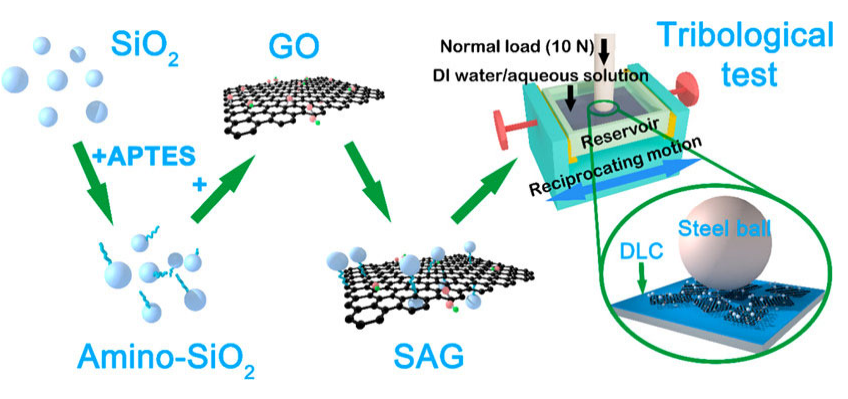

Fig. 5 The schematic diagrams of the synthesis and tribological test of silica modified GO. Reproduced with permission from Ref. [70], (c) American Chemical Society, 2020. 


\section{Metal oxides}

Versus nonmetal oxides, a combination of metal oxides with GO is more common in lubrication. Reports about GO-metal oxide composites in water lubrication are still limited and mainly focus on oil lubrication. The main application directions of GO-metal oxide composite in water lubrication are those scenarios that have higher requirement in heat transfer and environmental protection.

Common and cheap metal particles such as $\mathrm{Fe}_{2} \mathrm{O}_{3}$ [84], $\mathrm{CuO}$ [85], and $\mathrm{Al}_{2} \mathrm{O}_{3}$, are first adapted. Huang et al. [39] synthesized nanolubricants by mixing $\mathrm{GO}$ with $\mathrm{Al}_{2} \mathrm{O}_{3}$ nanoparticles in deionized water. The dispersion of $\mathrm{GO}-\mathrm{Al}_{2} \mathrm{O}_{3}$ was improved significantly versus single component dispersion. During the lubricant progress, GO films were strengthened by $\mathrm{Al}_{2} \mathrm{O}_{3}$ particles and the COF was reduced by $60 \%$ versus water. $\mathrm{GO}-\mathrm{Al}_{2} \mathrm{O}_{3}$ formed tribofilms with low shear and high mechanical strength, where $\mathrm{Al}_{2} \mathrm{O}_{3}$ could achieve more efficient polishing effect. The roughness of wear tracks was decreased significantly due to the synergy effect of $\mathrm{GO}$ and $\mathrm{Al}_{2} \mathrm{O}_{3}$.
Subsequently, the choice of introductions extends to other metal oxides including $\mathrm{TiO}_{2}, \mathrm{ZrO}_{2}$ and others. These candidates have better corrosion resistance and high temperature stability. Spherical nano- $\mathrm{TiO}_{2}$ was anchored on the GO nanosheet to obtain $\mathrm{GO}-\mathrm{TiO}_{2}$ via facile solvothermal reaction in Du et al.'s research [38]. The tribological properties and rolling lubrication performance were investigated in a control group and a single component dispersion liquid as well as a mixture of $\mathrm{GO}$ and $\mathrm{TiO}_{2}$ and $\mathrm{GO}-\mathrm{TiO}_{2}$ composites (Fig. 6). Among them, $\mathrm{GO}-\mathrm{TiO}_{2}$ had the highest maximal non-seizure load $\left(P_{\mathrm{B}}\right)$ value and the lowest $\mathrm{COF}$ and wear scar diameter. The cold-rolling lubrication experiments showed that the strip lubricated with GO- $\mathrm{TiO}_{2}$ nanofluid also exhibited the smallest rolling force, minimum rolling thickness, and rolled surface roughness due to the excellent dispersion stability and the formation protective and transfer films.

During the friction process, the fresh worn surface had sufficient energy such that the nanoparticles could easily adhere to the shear surface. The great dispersion of GO-metal oxides composites is beneficial to the ordered adsorption of these particles on the contact (a)
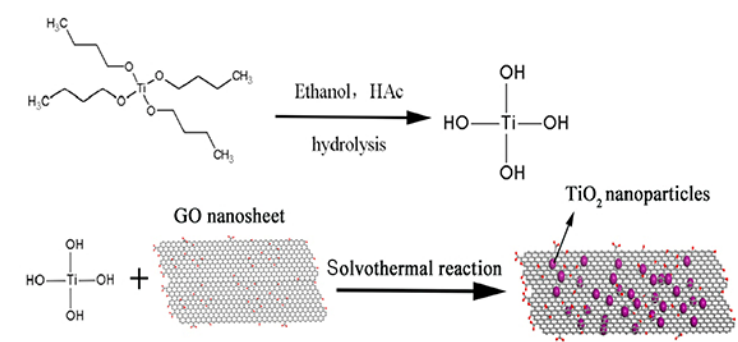

(b)

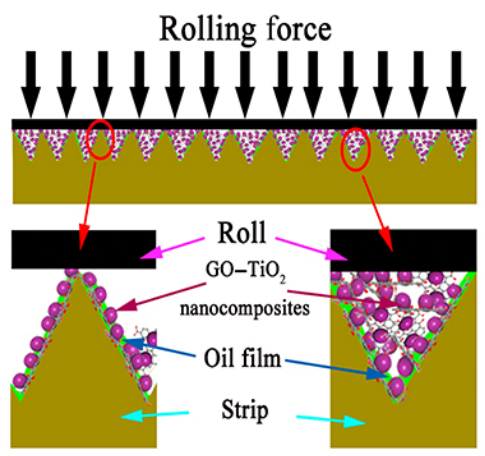

(c)

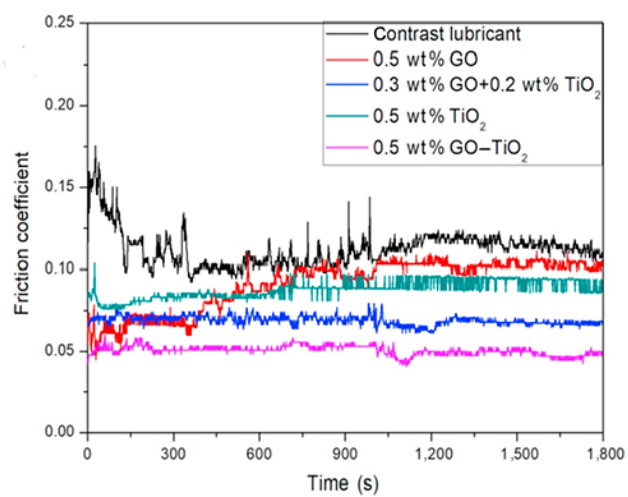

(d)

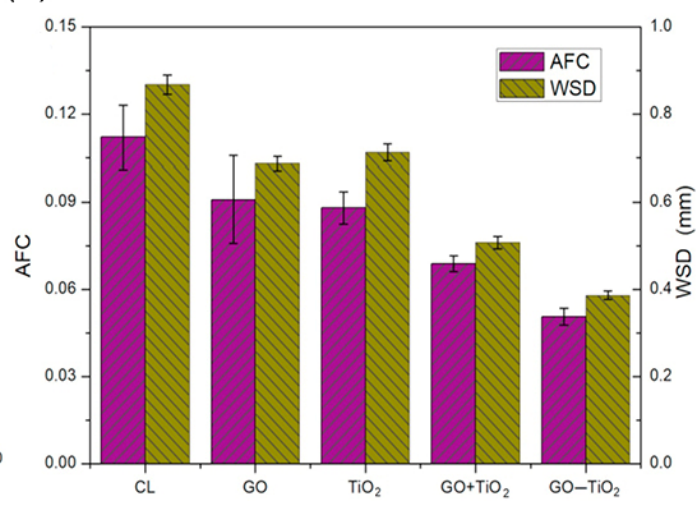

Fig. 6 (a) Schematic of the formation of $\mathrm{GO}^{-\mathrm{TiO}_{2}}$ nanocomposites. (b) Schematic diagram of lubrication mechanism. (c) Frictional curves, (d) average friction coefficient (AFM) and WSD of various lubricants. Reproduced with permission from Ref. [38], C Elsevier, 2018. 
areas. The composite tribofilms act as protective layers in situ on the worn surface and perform dynamic self-repair of worn surface. Besides, the nano-bearing mechanism works during the lubrication progress. Partial GO-metal oxide composites disintegrate and reorganize into smaller ones for the severe conditions, entering the contact areas more easily.

\subsubsection{GO-carbonaceous nanoparticle composite}

The variety of carbonaceous nanoparticles is diverse, including spherical fullerenes (C60, 0D) [86], carbon nanotubes (1D) [87, 88], GO and GO derivatives (2D) [89, 90], lamellar graphite (3D) [91], and diamonds (3D) [92]. In our previous research [93], we compared the tribological behavior of carbonaceous nanoparticles with different dimensions in aqueous system and found that GO can reduce the running-in period significantly versus other carbonaceous materials including graphite, carbon nanotube, and C60. These carbonaceous nanoparticles present totally diverse lubrication properties when applied to different application scenarios. The complementarity of different carbonaceous nanoparticles is anticipated.

Diamonds are the hardest substance in natural products. Wu et al. [73] mixed GO with nanodiamond and found that the novel lubricant had excellent performance. A COF of approximately 0.03 was obtained for aqueous solution with $0.1 \mathrm{wt} \%$ GO and $0.5 \mathrm{wt} \%$ nanodiamond. Meanwhile, the corresponding depth of the wear track was as low as about $5 \mathrm{~nm}$ under a normal load of 5-80 $\mathrm{mN}$. The interlayer slip of GO combined with the rolling bearing of nanodiamond effectively reduced friction and wear.

Carbon nanotubes are prepared by curling sheet-like graphene with unique hollow tubular structure. The elastic modulus and thermal conductivity of carbon nanotubes are attractive. However, the thermal conductivity has big difference in various orientations. The thermal conductivity in the direction parallel to the tube wall is much higher than that in the vertical direction. The dispersion of carbon nanotubes in polar solvents also needs improving; adding GO can help.

Min et al. [29] prepared GO nanosheets/carboxylfunctionalized multi-walled carbon nanotubes (MWCNTs-COOH) composites via vacuum filtration of a solution hybrid dispersion as an additive for water-based lubricants (Fig. 7). The results showed that the synergistic effect was the best when the ratio of GO and MWCNTs-COOH reached 3:1. The interlayer and tube space were extended for the connection of GO and MWCNTs-COOH, by $\pi-\pi$ noncovalent bonding. MWCNTs-COOH functioned as micro-bearers decreased the friction. In particular, the $\mathrm{COF}$ and wear rate were minimal when the concentration of the composites reached $0.7 \mathrm{wt} \%$.

Graphite is traditional lubricants with long history. He et al. [74] prepared a mixed suspension of graphitic carbon nitride and GO improving the unstable lubrication in pure graphitic carbon nitride or GO suspensions, under relatively high loads and speeds. The results showed that the mixed suspension had superior tribological performance in all tested conditions. The aggregation of graphitic carbon nitride agglomerates was realized in the mixed suspension. GO nanosheets exhibited fewer wrinkles and less stacking and formed more efficient tribo-composite films. As a result, the friction, wear volume, and tribocorrosion were reduced during sliding.

Therefore, reasonable collocation between GO and other carbonaceous nanoparticles performed more outstanding lubrication property due to the complementarity of each component. The carbonaceous materials acted as fortifiers to avoid the pollution from toxic heavy metal elements. The environmental friendliness of GO-carbonaceous nanoparticles is consistent with the original intention of water lubrication.

\subsection{GO-organic composite}

The introduction of organics enriches the application scenarios of GO. Various active groups introduced in GO affect the adsorption and change the quality of tribology films. The synthesis of GO-organic composite additives mainly uses GO as a matrix. The modified functional groups for GO include carboxyl groups, amine groups, and hydroxyl groups. The combination of organics and GO is mainly realized via the bonding reaction such as esterification or acylation actions.

The introduction with long carbon chains is used to achieve controllable activity of water-oil interface generally. Specifically, the polar groups have strong affinity with metals aiding to form stable lubrication 

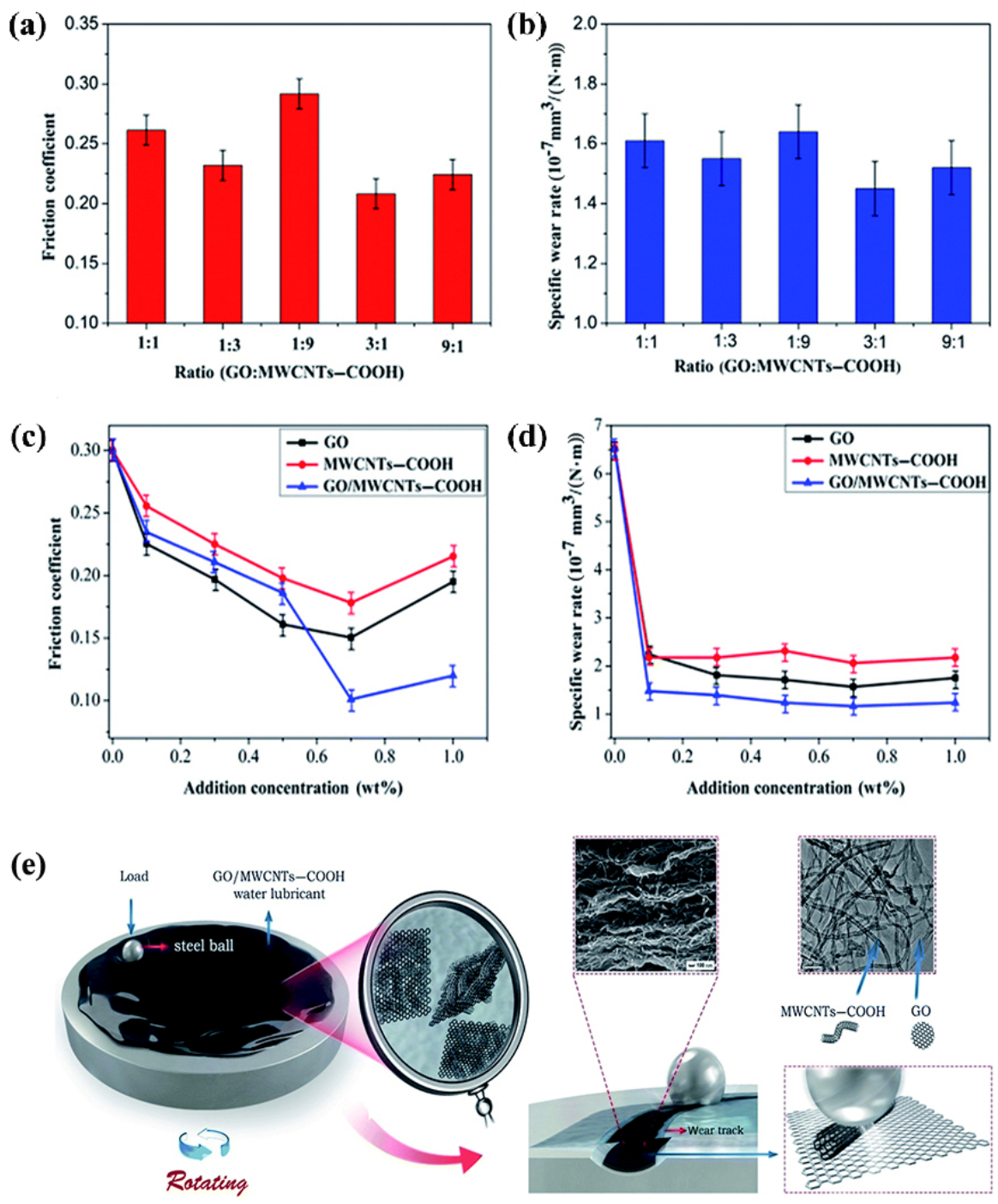

Fig. 7 (a) COF and (b) wear rates influenced by ratios of GO/MWCNTs-COOH in water lubrication. (c) COF and (d) wear rates influenced by concentration of GO, MWCNTs-COOH, and GO/MWCNTs-COOH (3:1) in water lubrication. (e) The lubrication mechanism of GO/MWCNTs-COOH hybrids as additives in water lubrication. Reproduced with permission from Ref. [29], (C) Royal Society of Chemistry, 2017.

layer together with GO. And the long carbon chains anchor the oil phase to the metal surface forming denser lubrication films. Therefore, the GO-organic composites perform superior lubrication property in oil-in-water emulsion. The variety, reaction sites, structure, and amounts of the introductions have a great influence on the tribology properties of composites (Fig. 8) [94-96].

The types of introductions directly determine the tribology behaviors. The polarity and active elements of the functional groups decide the adsorption strength between additives and friction pairs closely related to the antifriction and antiwear properties. Amines have great reaction activity with $\mathrm{GO}$ and are mostly grafted into GO by the nucleophilic substitution with epoxy groups and activated carboxyl groups. The active element of $\mathrm{N}$ can also associate the adsorption of GO on the contact surface. The prospect in lubrication and economic makes amine important introductions to GO. The application of amine-modified GO involves both oil lubrication and water lubrication [97]. Wu et al. [75] synthesized asymmetrically modified GO with introduced myristyltrimethylammonium bromide (TTAB); a Pickering emulsion was made from the modified GO. The modified GO significantly improved the stability of base emulsion reflecting the decrease 
(a)

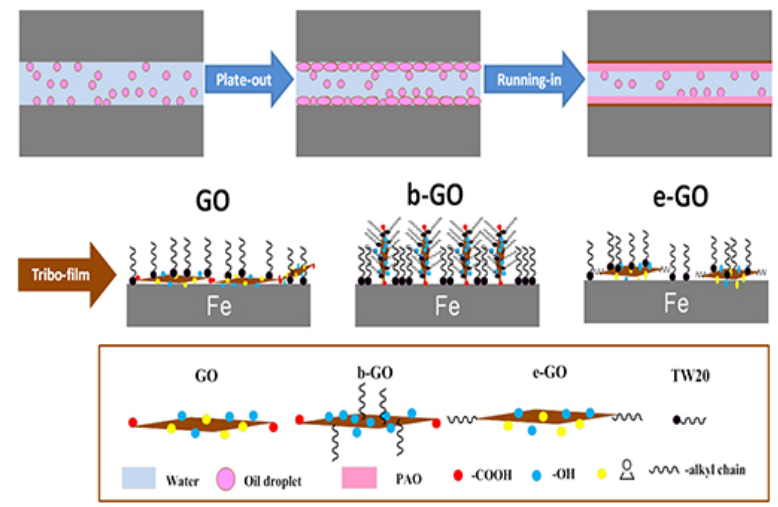

(b)

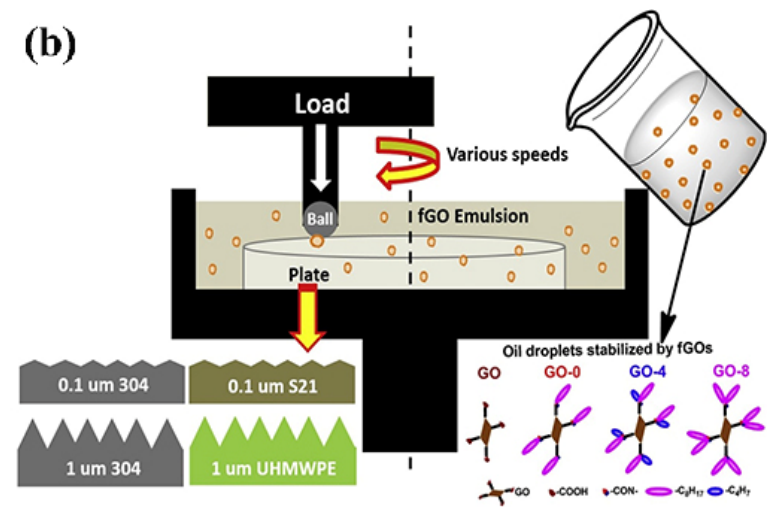

(c)

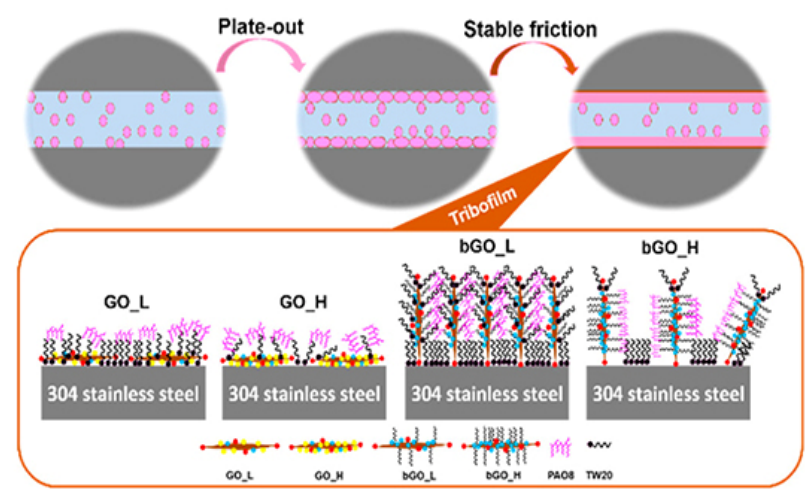

Fig. 8 The influence of (a) reaction sites (Reproduced with permission from Ref. [77], ( American Chemical Society, 2018), (b) structure (Reproduced with permission from Ref. [78], (C) Elsevier, 2019), and (c) amounts of introductions combined with GO on tribology property (Reproduced with permission from Ref. [79] (C) American Chemical Society, 2019).

of droplet size. In the meantime, the COF and the wear rate of the steel ball decreased by $18 \%$ and $48 \%$, respectively, based on the emulsion lubrication. The superior performance is attributed to a strong filmforming ability on the metal surface and good lubricity of the small droplets. Sun et al. [76] utilized triethanolamine-modified GO as an additive in water. The results showed that the average COF and wear scar diameter of $0.1 \mathrm{wt} \%$-modified GO dispersion decreased by $21.9 \%$ and $6.2 \%$ versus $0.1 \mathrm{wt} \% \mathrm{GO}$ aqueous solution. The minimum of the COF and wear scar diameter appeared in $0.3 \mathrm{wt} \%$ modified GO dispersion.

The different reaction sites between GO and introductions have great influence on the performance of GO composites. Yang et al. [77] synthesized the edge-functionalized GO (e-GO) and basal plane functionalized GO (b-GO) with n-octylamine by controlling the relative reactivity of functional groups, respectively. The thickness of b-GO is more than two-fold as much as that of e-GO. The wrinkles in
b-GO were mainly distributed on edges while those of e-GO were mostly distributed on basal planes. Reflecting the macroscopic properties, even if e-GO had broader interfacial tension-reducing capability, its lubricant property was inferior to b-GO for the poor lubrication layer in water-based lubrication.

The interfacial activity and lubrication of GO composites differ due to structure of introductions. Yang et al. [78] explored the influence on physicochemical and lubrication properties due to the introduction with diverse branch-chain length. The GO composites were prepared via octylamines containing different branchchain lengths $(C=0,4,8)$ under the same conditions. The results showed that the wrinkles of GO composite were realized via increased branch-chain length gradually due to weakening intermolecular hydrogenbond interactions. Subsequent testing proved that the moderate branch-chain length $(\mathrm{C}=4)$ brought the modified GO the best lubrication property. However, the composite with least branch-chain lengths $(\mathrm{C}=0)$ exhibited best interfacial property. 
The amounts of introductions on GO influence the interfacial assembly behavior and are related to the interfacial arrangement and lubrication effects. In our previous work [79], we explored the oil-water interfacial activity and lubrication performance about the amounts of introductions. The alkylamines were introduced on the basalt plane of $\mathrm{GO}$, and the extent of grafting was controlled via GO with different degrees of oxidation. GO with fewer introductions had broader capability to modulate interfacial tensions and better lubrication property. However, more introduction in the GO improved superior anticorrosion performance for the dense, ordered, and hydrophobic films on the metal surface.

\section{GO composite applied in frictional pairs for water lubrication}

The utilization of GO as a dispersion additive reduces the wear of the frictional pairs and repairs worn defects. However, it cannot change the inherent properties of frictional pairs or improve the antifriction properties of the substrate(s). Therefore, it is an effective and common way to improve the mechanical, antifriction, and anticorrosion property of frictional pairs incorporating GO-based composites into frictional pairs, including as a coating on the surface and as a filler in the matrix of the frictional pair.

\subsection{GO-based coating on the surface of frictional pairs}

This is a traditional and impactful way to protect frictional pairs from constant wear and corrosion by coating. GO with abundant functional groups can generate firm absorption with substrate, and thus GO coating is widely taken in oil-based and dry friction [98-101]. For instance, Liu et al. [102] prepared $\mathrm{MoS}_{2}-\mathrm{GO}$ coatings on the surface of stainless-steel substrates by electrophoretic deposition. The effective protection from surrounding GO protected the $\mathrm{MoS}_{2}$ away from humidity and oxidation so that $\mathrm{MoS}_{2}$ could exert its easy-shear property efficiently. Singh et al. [98] coated frictional pairs uniformly with $\mathrm{Ni}-\mathrm{GO}$ nanocomposite. The results confirmed that the Ni-GO coating significantly reduced COF and wear scar depth especially at a low slide speed.
However, the lubrication of GO coating in high humidity condition is unstable. The hydrogen bonds formed by water molecules and oxygen functional groups of GO aggregate shear resistance, generate coating wrinkles, and destroy the orderly layered structure. To apply GO coating into water lubrication, one of the strategies is to hydrophobically modify GO to reduce the impact. Wang et al. [103] found an optimal balance between oxygen-containing functional groups and defects on GO where GO coating exhibits the best lubrication performance. In fact, replacing GO with GO composites as a coating is a more effective way (Fig. 9). The chemical bonding with other substances strengthens the adhesion of coating and increases the durability of GO coating under shearing. Various GO composites have been applied as a coating in recent research (Table 5).

$\mathrm{Li}$ et al. [104] fabricated GO-3-aminopropyltriethoxysilane (GO-3-APS) film on a bronze substrate resulting in durable lubrication film during water lubrication. The additional results showed that the $\mathrm{COF}$ and the wear rate of the composite coating decreased by $43.6 \%$ and $79.7 \%$ versus blank substrate under pure water lubrication. The composites also behaved great synergistic effects versus pure GO or pure 3-APS. Cao et al. [105] fabricated a new poly (phthalazione ether sulfone ketone) (PPESK)-GO composite coating on the surface of high strength glass fabric substance by electrophoretic deposition. The results proved that the addition of GO improved the antiwear and interfacial adhesion property. GO on the fiber surfaces shared partial applied load on the fibers, so that the stress concentration was reduced and the fibers were not easy to break out.

In Sadeghi et al.'s research [106], polyvinyl pyrrolidone (PVP) was deposited on a GO coating for double-layer coatings on Ti6Al4V substrates with laser texturing process by electrophoretic deposition. Tribology tests proved that the double layer coatings reduced COF from 0.5 to less than 0.03. GO-PVP coating also had great biocompatibility and promising prospects in clinical applications. The improvements in lubrication property benefited from a combination between smooth surface of PVP for suitable adhesion and dense GO film for load bearing. The textured micro-dimples also preserved the fragments and wear 
debris avoiding worse wear. Wu et al. [107] synthesized coatings on cast iron, utilizing a mixture of epoxy resin (EP) with graphene or GO. The research compared the lubrication effect of various coatings under dry and artificial seawater conditions. GO-EP coatings had better tribological performance than graphene-EP coating. GO-EP coating containing $0.75 \mathrm{wt} \% \mathrm{GO}$ exhibited best tribology properties under seawater, where the coating had the lowest COF and best wear resistance. The excess part would decrease the lubrication effect due to agglomeration of the fillers.

\subsection{GO-based fillers in a matrix of frictional pairs}

GO composite fillers are widely used in polymeric friction pairs [108]. Polymers have taken the place of traditional metal materials in several tribology scenarios in recent years due to low density, outstanding corrosion resistance, and chemical inertness. The abundant functional groups of GO can strengthen the cross-linking of polymers and significantly improve Young's modulus and tensile strength, thus reducing the destroying in deformation under high load. Besides, (a)
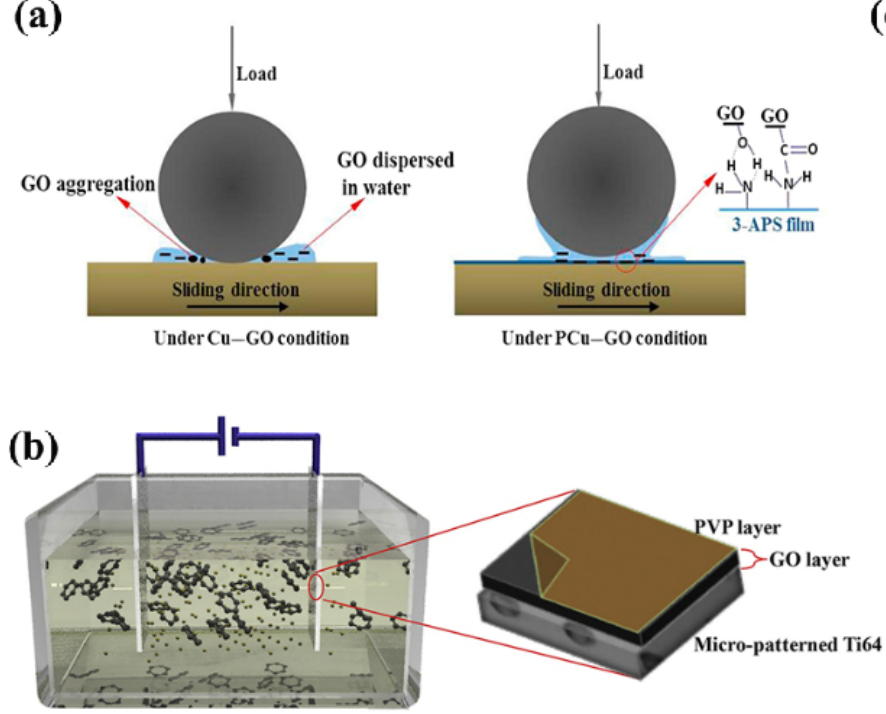

(c)

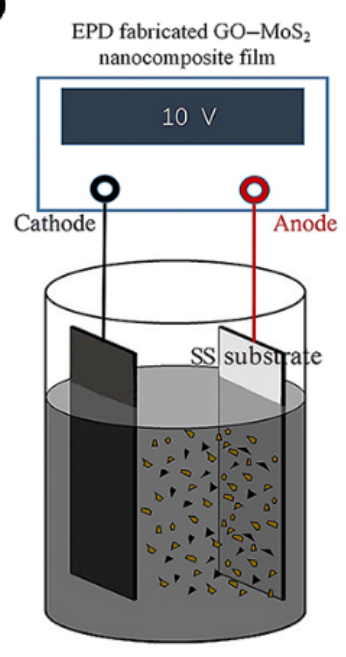

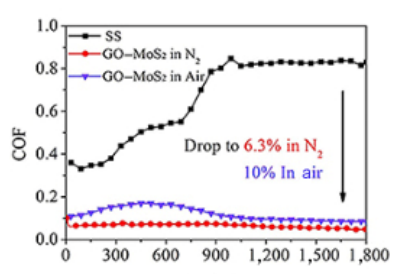

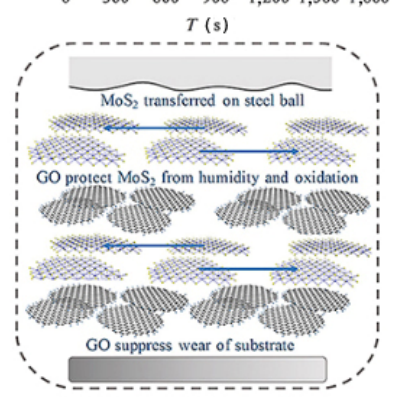

Fig. 9 GO-composites coatings. (a) Lubrication mechanisms of 3-APS/GO coating. Reproduced with permission from Ref. [104], (C) Elsevier, 2018. (b) Fabrication of PVP/GO double layer coating. Reproduced with permission from Ref. [106], (C) Elsevier, 2019. (c) Synthesis of the GO-MoS 2 nanocomposite film, the tribology property, and lubrication mechanism of GO-MoS 2 . Reproduced with permission from Ref. [102], (C) Elsevier, 2019.

Table 5 The summary of GO based coating on the surface of frictional pairs.

\begin{tabular}{|c|c|c|c|c|c|c|}
\hline Composites & Tribology properties & Other performance & $\begin{array}{l}\text { Lubrication } \\
\text { system }\end{array}$ & Substrate & Test conditions & Ref. \\
\hline GO-3-APS & $\begin{array}{c}\text { Reduction in COF } 43.6 \% \\
\text { Reduction in wear rate: } \\
79.7 \%\end{array}$ & - & Water & Albronze plates & $\begin{array}{l}\text { Load: } 2 \mathrm{~N}(381 \mathrm{MPa}) \\
\text { Velocity: } 0.012 \mathrm{~m} / \mathrm{s} \\
\text { Temperature: } 25^{\circ} \mathrm{C}\end{array}$ & {$[104]$} \\
\hline GO-PPESK & $\begin{array}{l}\text { The running-in period is } \\
\text { significantly reduced. } \\
\text { The wear rate decreased by } \\
\text { almost } 1 / 3\end{array}$ & $\begin{array}{l}\text { The interlaminar shear } \\
\text { strength of the composites } \\
\text { was enhanced by } 36.04 \% \text {. }\end{array}$ & Water & $\begin{array}{l}\text { High-strength } \\
\text { glass fabric }\end{array}$ & $\begin{array}{c}\text { Load: } 200 \mathrm{~N} \\
\text { Velocity: } 0.5 \mathrm{~m} / \mathrm{s}\end{array}$ & {$[105]$} \\
\hline GO-PVP & $\begin{array}{l}\text { COF reduced from } \\
0.5 \text { to }<0.03\end{array}$ & $\begin{array}{l}\text { GO coating improved the } \\
\text { wear resistance and } \\
\text { biological function. }\end{array}$ & $\begin{array}{l}\text { Water/ } \\
\text { normal } \\
\text { saline }\end{array}$ & $\begin{array}{l}\text { Ti6Al4V by laser } \\
\text { texturing process }\end{array}$ & $\begin{array}{l}\text { Load: } 1,2,4,6 \mathrm{~N} \\
\text { Velocity: } 0.1 \mathrm{~m} / \mathrm{s}\end{array}$ & {$[106]$} \\
\hline GO-EP & $\begin{array}{l}\text { Coating containing } 0.75 \% \\
\text { GO behaved the lowest COF } \\
\text { and best wear resistance }\end{array}$ & - & $\begin{array}{c}\text { Water/sea } \\
\text { water }\end{array}$ & Cast irons & $\begin{array}{l}\text { Load: } 2 / 3 \mathrm{~N} \\
\text { Velocity: } 5 \mathrm{~Hz}\end{array}$ & {$[107]$} \\
\hline
\end{tabular}


the improvement in antifriction property also profits from the formation of GO transfer film with low shear strength on the friction interface during sliding. In short, applying GO or GO composites into substrates can change their inherent properties. The improvement in mechanical, antifriction, and anticorrosion property reduced the damage of substrates $[109,110]$. The synergy effect between GO composite and polymeric friction pairs was also proved by molecular dynamic simulation [111]. Table 6 shows that GO composites as a filler have attracted great attention.

Several researches into GO fillers with carbon chain polymers, including polyene and rubber have been reported. Vadivel et al. [112] synthesized a new type of hybrid composite with ultra-high molecular weight polyethylene (UHMWPE) as a base polymer and mixture of GO, nanodiamonds, and short carbon fibers as fillers. Under water friction testing, the composites exhibited obvious synergistic effect with a decrease of $21 \%$ in COF and $15 \%$ in specific wear rate respectively, compared to unfilled UHMWPE. The oxidation, degradation temperature, and index of service life of the composite were also significantly improved. Li et al. [109] prepared GO/nitrile rubber nanocomposites with various contents of GO by a solution-mixing method. The GO/nitrile rubber nanocomposites had obvious improvements versus nitrile rubber substrates under dry sliding and water-lubricated conditions. In the water lubrication test, both COF and specific wear rate were decreased with increasing GO contents over the range of $0-3 \mathrm{wt} \%$. The $\mathrm{COF}$ and specific wear rate were the lowest when adding 3\% GO thus reducing them by $12 \%$ and $10 \%$, respectively.

The application of GO in heterocyclic polymer also has raised concerns. Yin et al. [113] compared the different performance of polyetheretherketone (PEEK)/GO under water lubrication or PEEK lubricated by GO aqueous solution. The GO aqueous solution decreased the COF and wear by $55 \%$ and $94 \%$, respectively, versus pure water. In contrast, GO added to PEEK was less efficient; the COF and wear reduced by $30 \%$ and $25 \%$, respectively. The strong adherence of GO to the PEEK resulted in an in situ-formed GO coating and prevented scratching from the steel counterpart. Min et al. [114] reported a novel fluorinated GO/polyimide (FGO/PI) nanocomposite via simple hydrothermal reactions (Fig. 10). The tribology tests were performed under dry friction and sea water friction (simulating ocean environmental). The composite performed the best lubrication properties in both test conditions at GO concentration of $0.5 \mathrm{wt} \%$. The COF and specific wear rate decreased by almost 33.1\%/ $80.8 \%$ and $26.7 \% / 94.5 \%$ under dry friction and seawater friction, respectively. Notably, GO-PI manifested better antiwear property under seawater than that under dry friction, illustrating its great potentiality as a high

Table 6 The summary of GO based fillers in a matrix of frictional pairs.

\begin{tabular}{|c|c|c|c|c|c|c|}
\hline Composites & Optimum & Tribology properties & Other performance & $\begin{array}{c}\text { Lubrication } \\
\text { system }\end{array}$ & Test conditions & Ref. \\
\hline $\begin{array}{l}\mathrm{GO} / \text { nano } \\
\text { diamonds/short } \\
\text { carbon fibers- } \\
\text { UHMWPE }\end{array}$ & $\begin{array}{c}0.5 \text { wt } \% \text { GO; } \\
0.5 \text { wt } \% \text { nano } \\
\text { diamonds; } 10 \% \\
\text { short carbon fibers }\end{array}$ & $\begin{array}{l}\text { Reduction in COF: } 21 \% \\
\text { Reduction in wear: } 15 \%\end{array}$ & $\begin{array}{l}\text { Oxidation and degradation } \\
\text { temperatures were } \\
\text { significantly delayed. }\end{array}$ & Water & $\begin{array}{l}\text { Load: } 5 \mathrm{MPa} \\
\text { Velocity: } \\
0.13 \mathrm{~m} / \mathrm{s} \\
\text { Temperature: RT }\end{array}$ & [112] \\
\hline $\begin{array}{l}\text { GO-nitrile } \\
\text { rubber }\end{array}$ & $3 \mathrm{wt} \% \mathrm{GO}$ & $\begin{array}{l}\text { Reduction in COF: } 12 \% \\
\text { Reduction in wear: } 10 \% \\
\text { (when addition of } \\
\text { GO reached 3\%) }\end{array}$ & - & Water & $\begin{array}{c}\text { Load: } 10 \mathrm{~N} \\
\text { Velocity: } 200 \mathrm{rpm} \\
\text { Temperature: } 20^{\circ} \mathrm{C}\end{array}$ & [109] \\
\hline GO-PEEK & $0.1 \mathrm{wt} \% \mathrm{GO}$ & $\begin{array}{l}\text { Reduction in COF: } 30 \% \\
\text { Reduction in wear: } 25 \%\end{array}$ & $\begin{array}{l}\text { Adding GO into lubricant } \\
\text { liquid behaved better } \\
\text { tribology performance than } \\
\text { adding GO into PEEK } \\
\text { matrix. }\end{array}$ & Water & $\begin{array}{c}\text { Load: } 80-100 \mathrm{~N} \\
(6.7-50 \mathrm{MPa}) \\
\text { Velocity: } 0.1 / 0.7 \mathrm{~m} / \mathrm{s} \\
\text { Temperature: } \\
25 \pm 5{ }^{\circ} \mathrm{C}\end{array}$ & [113] \\
\hline GO-PI & $\begin{array}{l}\text { Composite } \\
\text { containing } 0.5 \mathrm{wt} \% \\
\text { FGO behaved the } \\
\text { best tribology } \\
\text { property. }\end{array}$ & $\begin{array}{l}\text { Reduction in COF: } \\
\text { almost } 33 \% \\
\text { Reduction in wear: } \\
\text { almost } 80 \%\end{array}$ & $\begin{array}{l}\text { The thermal stability, } \\
\text { tensile strength, and } \\
\text { abrasion resistance had } \\
\text { richest enhancement when } \\
\text { FGO reached } 1 \% .\end{array}$ & $\begin{array}{l}\text { Water/sea } \\
\text { water }\end{array}$ & $\begin{array}{c}\text { Load: } 5 \mathrm{~N} \\
\text { Velocity: } 0.094 \mathrm{~m} / \mathrm{s}\end{array}$ & [114] \\
\hline
\end{tabular}


(a)

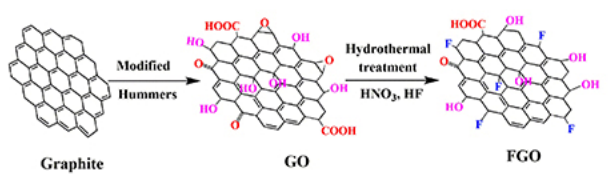

(b)

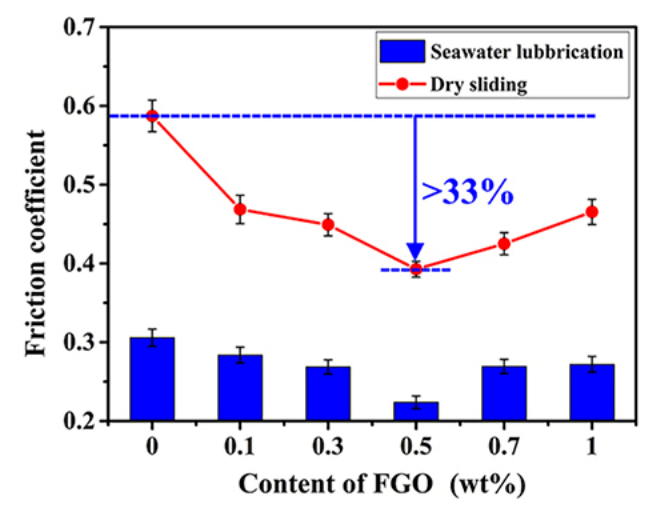

(c)

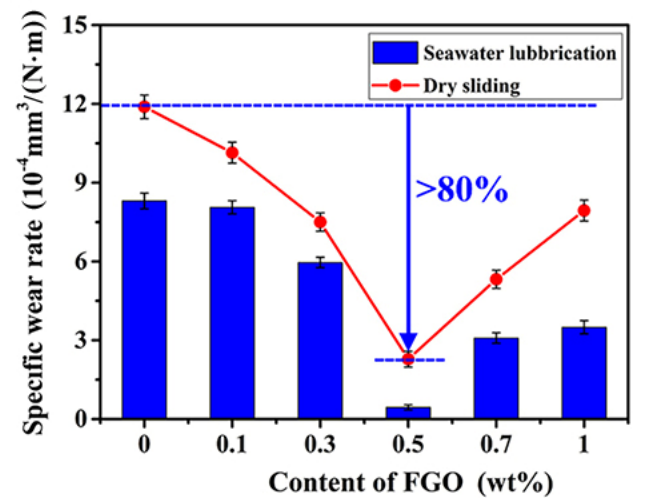

Fig. 10 (a) Synthesis process of PI/FGO nanocomposite films. (b) COF and (c) specific wear rate of PI/FGO composites with various content of GO under different lubricating conditions. Reproduced with permission from Ref. [114], @ John Wiley and Sons, 2019.

wear-resistant material suitable for the ocean.

\section{Application of GO-based materials in water lubrication}

The most common application scenario of water lubrication is focused on the water-based metalworking process and bio-lubrication. The utilization of low amounts of GO significantly improves the lubrication performance. The application of GO-based materials in water lubrication is promising because the productions of GO and GO derivatives are industrialized.

\subsection{Application of GO in water-based cutting fluids}

Metalworking is basis of industrial production. In the traditional metalworking progress, the cutting fluid was mainly made up of mineral oil that causes enormous consumption and pollution. Metalworking has a high requirement for the thermal conductivity of cutting fluid where the performance of oil-based cutting fluid was not satisfied [115]. The energy produced during the cutting process will decrease the quality of workpieces and generate toxic oil mist. However, these problems seem to be well solved in water-based metalworking fluid. The utilization of water-based cutting fluids not only reduces the productive and environmental cost but also cools and sweeps the metal surface restraining built-up edges. The anti-corrosion properties of cutting fluids in the process of machining are essential to guarantee the quality of products. Our previous work indicated that $\mathrm{GO}$ behaved certain anti-corrosion properties in water lubrication, especially in water-based emulsion. The hydrophobic modification of GO exhibited better anti-corrosion properties than pristine GO. In actual conditions, it would be more effective to cooperate GO with other corrosion inhibitor.

Li et al. [116] tested the performance of GO aqueous solution in the precision grinding of $\mathrm{Si}$ and $\mathrm{GaAs}$ substrates in terms of tangential force, force ratio, and surface quality. The results proved that the GO aqueous solution exhibited better performance at $0.1 \mathrm{wt} \%$. The formation of dynamic lubricating film of GO at the wheel-substrate elevated the interface grinding performance. Lv et al. [72] prepared water-based cutting 
(a)

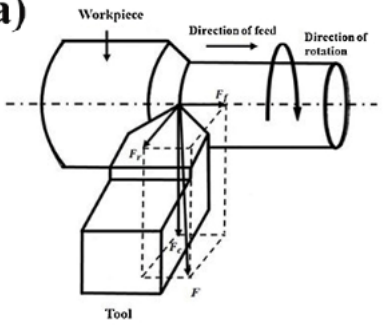

(c)
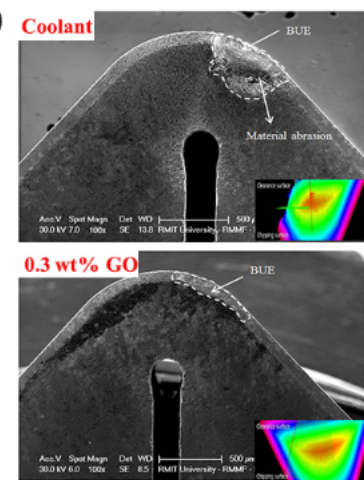
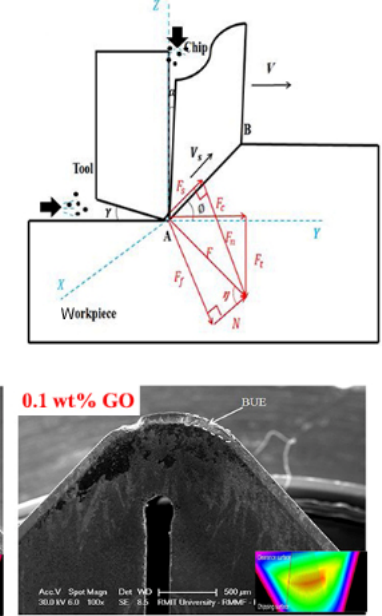

$0.5 \mathrm{wt} \% \mathrm{GO}$

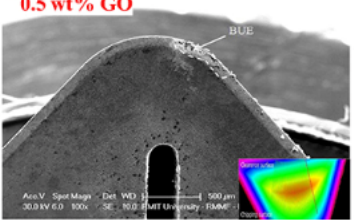

(b)

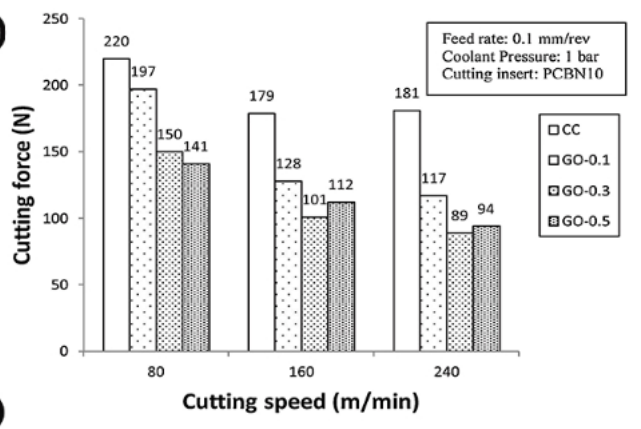

(d)

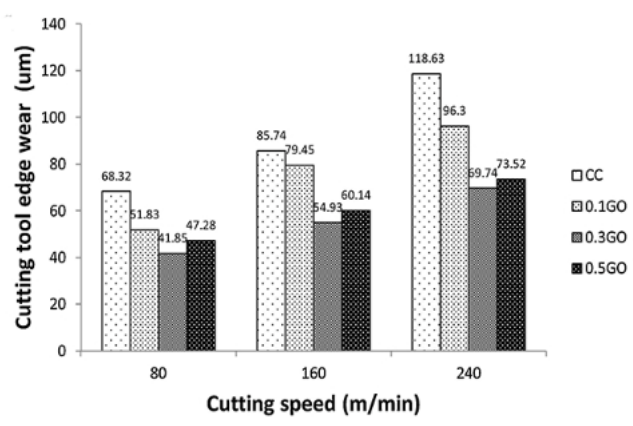

Fig. 11 (a) Force distribution and nanofluids effects in cutting area. (b) The change of Cutting forces with cutting speed. (c) SEM images of rake face with conventional coolant and GO suspension of various concentration. (d) The change of Cutting tool edge wear with cutting speed. Reproduced with permission from Ref. [117], () Elsevier, 2020.

fluid with $\mathrm{GO} / \mathrm{SiO}_{2}$ hybrid nanoparticles. The results proved that composites containing $0.02 \mathrm{wt} \% \mathrm{GO}$ and $0.5 \mathrm{wt} \% \mathrm{SiO}_{2}$ exhibited the best antifriction and antiwear properties, where the reduction in COF and wear was $19.5 \%$ and $8.5 \%$ higher than individual GO dispersion. Yi et al. [117] applied types of GO nanofluids in metal cutting. The tool wear, cutting force, and the vibration in turning titanium alloy were tested (Fig. 11). The cutting force reduced up to 50.83\% with GO nanofluids compared to conventional coolants. The built-up edge and attrition wear were decreased when the GO coolant was taken. Under lower feed rate and higher coolant pressure, it appeared lower cutting vibration. Besides, the cutting performance was not positively correlated with the GO concentration at high concentrations.

The improvement in heat conduction was also notable and affected the processing quality and precision evidently. Yi et al. [118] changed chip formation, cutting temperature, and surface roughness in turning Ti-6Al-4V with GO nanofluids. The cutting temperature, chip thickness, and chip compression ratios were obviously decreased with GO nanofluids. The scratch and plastic deformations reduced. The average surface roughness was reduced by $27.51 \%$ with GO nanofluid.

Due to the amphiphilicity of GO, it can act both a lubricant additive and a surfactant. Thus, it can be used to construct semisynthetic cutting fluid, i.e., a Pickering emulsion. The interfacial property of GO mainly originates from the hydrophilic oxygencontaining functional group and hydrophobic carbon skeleton. The aromatic ring skeleton structure of pristine GO restricts the emulsified oil phase to the toxic aromatic hydrocarbons. The alkylation of GO improves its interfacial property and broadens the types of the emulsified oil. In our previous work [119], we prepared GO-based Pickering emulsion as water-based cutting fluid through a combination of functionalized GO and commercial cutting fluids. The tribology tests proved that the performance is diverse and is influenced by the structure of the functionalized GO and the type of the commercial cutting fluids. Overall, the antifriction, tapping torque property, and thermal conductivity appeared to improve differently with GOs. The analysis of wear tracks indicated that adding $\mathrm{GO}$ generated effective lubricant films. 


\subsection{Application of GO in bio-lubrication}

Bio-lubrication uses lubrication theory and methods for friction pairs in biological systems. It studies the tribological problems of biological systems or external surfaces of biological systems including the friction between human body replacement joints and biological tissues [120-122], the adhesion of blood on artificial implant [123, 124], tooth wear [125-127], and skin friction [128, 129].

Considering that water is the main component in body fluids and accounts for $70 \mathrm{wt} \%$ of the human body, the application scenarios of water lubrication can also be extended to bio-lubrication. The mechanical properties, chemical inertness, and relative antibacterial properties [130, 131] of GO materials attracted the interests of researchers to explore the potential application in bio-lubrication. Previous reports proved that the biocompatibility of GO is related to the factors such as physical-chemical properties, concentration, time of exposure and so on. The extant reports stated that GO materials behave hemocompatible and relative inhibition to several cell viability [132-134]. The biocompatibility needs to be careful and long-term exploration. The application of GO based materials in biological systems, e.g., in artificial joint replacement, reduces friction loss and extends service life significantly and performs promising prospect.

UHMWPE is commonly used in bio-lubrication due to its low COF, good biocompatibility, and stability. An et al. [110] prepared a GO-modified UHMWPE and tested its lubrication property against $\mathrm{ZrO}_{2}$ under deionized water and normal saline solution simulating the friction progress in body fluid environments (Fig. 12). The results showed the microhardness of the GO/UHMWPE composites increased. The tribology performance had a similar trend in deionized water and normal saline solution showing that the COF increased slightly but the antiwear property improved significantly. They attributed the improvement to the well-distributed GO and the transformation from fatigue wear to abrasive wear after the addition of GO.

Ren et al. [135] synthesized a GO/PEG/CS (chitosan) (a)

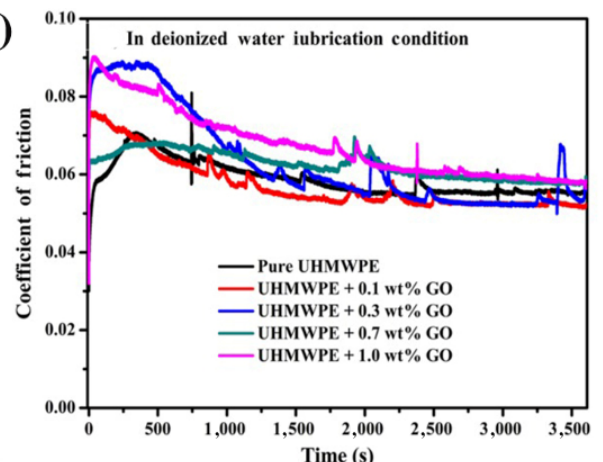

(c)

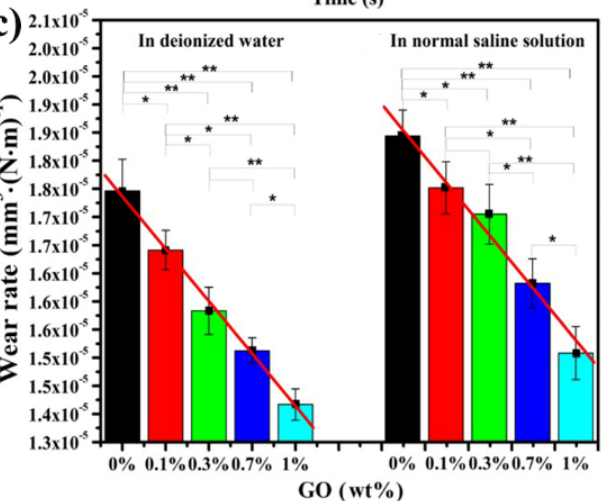

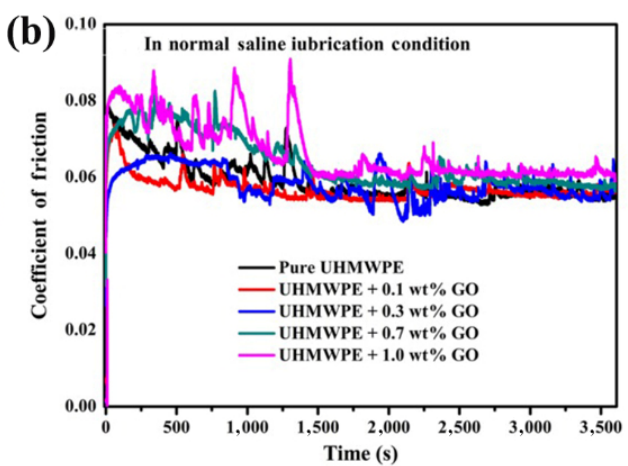

(d)

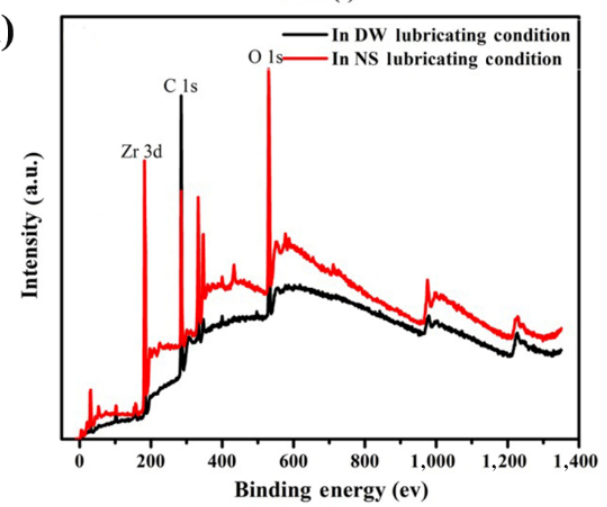

Fig. 12 Frictional curves of the GO/UHMWPE composites under (a) deionized water (DW) lubrication and (b) normal saline (NS) lubrication. (c) Wear rate of the GO/UHMWPE composites under deionized water lubrication and normal saline lubrication. (d) XPS results from the surface of the balls after wear testing in DW and NS lubricating conditions. Reproduced with permission from Ref. [110], (C) John Wiley and Sons, 2014. 
sol and stored it in a dimpled texture of $\mathrm{Co}-\mathrm{Cr}-\mathrm{Mo}$ alloy. The novel gel offered controlled release of GO/PEG lubricants avoiding rapid degradation and absorption by the human body and prolonging the lubrication effect. The tribology results proved that the average COF of the slow-release solution is below 0.025 , which is better than the performance of composites without GO. The gel also presented superior lubrication effects under textured or non-textured contact surface. The superior lubrication property with sustained release and friction proves that the controlled release was effective.

\section{Summary and outlook}

GO exhibits outstanding mechanical, thermal, and tribology properties. The great water dispersibility and reaction activity brought by the abundant oxygen containing makes GO an ideal lubricant in water lubrication. The economic and environmental superiorities of GO are strengthened by the innovation in synthesis. Lubrication efficacy is improved by the optimization of factors in concentration, oxidation degrees, $\mathrm{pH}$ value and others. Combining GO with other substances strengthens the antifriction performance and expands the application scenarios.

Although the water lubrication of GO has achieved breakthrough, there is still a lot of doable work in the future. (1) For the lubrication mechanism of GO, the current research is mainly focused on the solid lubrication of graphene in microscale. Due to the abundant oxygen containing groups of GO, the adsorption and formation of tribofilms during the water lubrication is different from graphene. Relevant exploration is urgent and valuable. Molecular dynamic simulation is a great way to analyze the atomic behaviors of GO in lubrication. The existing reports rarely discuss the dynamic process of adsorption and shearing off about GO in water lubrication. Besides, the ignorance of the influence of water molecular cannot reflect the real tribology progress. (2) For the factors affecting the lubrication efficacy of GO, systematic and in-deep work is needed. Although the cost of GO is decreasing, the large-scale use in industry is still very expensive. The efficient and stable lubrication at low concentration has significant meanings for the industrial application, by the optimization of these factors. Among them, the effects of the lateral size and thickness of GO need to be enhanced especially. Moreover, the mechanism analysis between the lubrication efficacy and the influence factors is helpful to accelerate the optimization progress. (3) For the application of GO-composites, it would be better to expand the range of introductions. GO-composites with diverse functions and excellent performance still need to be developed. (4) For the application of GO-based materials, the relevant research acquires deep and meticulous research. For example, the anticorrosion properties of GO-based materials in aqueous dispersion need more work, which has great significance for production. The biocompatibility of GO also needs to be careful and long-term exploration. In addition, the application fields of GO water lubrication should be enriched.

Notably, the water lubrication of GO appears some new trends. The superlubricity as an ideal tribology state achieves amazing lubrication efficacy. The current research proved that the superlubricity of GO in macroscale is accessible in aqueous dispersion. But it acquires continuous exploration in the structural design of GO and the corresponding construction of lubrication system. The improvement of stability and lubrication properties under severe test conditions is significant for the promotion of GO superlubricity in industry. Besides, GO with both tribology and interface properties can be used to construct water-based Pickering emulsion that performs potential application in water lubrication. It will be valuable to reveal the micro arrangement of $\mathrm{GO}$ in oil-water interface and analyze the further tribological behaviors with the development of new in-situ characterization technologies.

In summary, although challenges and problems remain, GO-based materials show bright and exciting prospects in the field of tribology and lubrication. The utilization of GO will be more efficient as the lubrication mechanism and structure of GO become more understood. The water lubrication of GO-based materials especially in metalworking and bio-lubrication will produce significant and positive results for manufacturing. 


\section{Acknowledgements}

The research was funded by the National Natural Science Foundation of China (No. 21703279) and the Science and Technology Development Fund of the Pudong New District (No. PKJ2020-N007).

Open Access This article is licensed under a Creative Commons Attribution 4.0 International License, which permits use, sharing, adaptation, distribution and reproduction in any medium or format, as long as you give appropriate credit to the original author(s) and the source, provide a link to the Creative Commons licence, and indicate if changes were made.

The images or other third party material in this article are included in the article's Creative Commons licence, unless indicated otherwise in a credit line to the material. If material is not included in the article's Creative Commons licence and your intended use is not permitted by statutory regulation or exceeds the permitted use, you will need to obtain permission directly from the copyright holder.

To view a copy of this licence, visit http://creativecommons.org/licenses/by/4.0/.

\section{References}

[1] Xiao H P, Liu S H. 2D nanomaterials as lubricant additive: A review. Mater Des 135: 319-332 (2017)

[2] Tiwari S K, Mishra R K, Ha S K, Huczko A. Evolution of graphene oxide and graphene: From imagination to industrialization. ChemNanoMat 4(7): 598-620 (2018)

[3] Liu Y F, Ge X Y, Li J J. Graphene lubrication. Appl Mater Today 20: 100662 (2020)

[4] Paul G, Hirani H, Kuila T, Murmu N C. Nanolubricants dispersed with graphene and its derivatives: An assessment and review of the tribological performance. Nanoscale 11(8): 3458-3483 (2019)

[5] Wu L P, Gu L, Jian R R. Lubrication mechanism of graphene nanoplates as oil additives for ceramics/steel sliding components. Ceram Int 47(12): 16935-16942 (2021)

[6] Ni J, Feng G D, Meng Z, Hong T, Chen Y B, Zheng X. Reinforced lubrication of vegetable oils with graphene additive in tapping ADC12 aluminum alloy. Int J Adv Manuf Technol 94(1-4): 1031-1040 (2018)

[7] Kogovšek J, Kalin M. Lubrication performance of graphene-containing oil on steel and DLC-coated surfaces. Tribol Int 138: 59-67 (2019)
[8] Brodie B C. On the atomic weight of graphite. Philos Trans Roy Soc London 149: 249-259 (1859)

[9] Staudenmaier L. Verfahren zur darstellung der graphitsäure. Ber Dtsch Chem Ges 31(2): 1481-1487 (1898)

[10] Hummers Jr W S, Offeman R E. Preparation of graphitic oxide. J Am Chem Soc 80(6): 1339-1339 (1958)

[11] Marcano D C, Kosynkin D V, Berlin J M, Sinitskii A, Sun Z Z, Slesarev A, Alemany L B, Lu W, Tour J M. Improved synthesis of graphene oxide. ACS Nano 4(8): 4806-4814 (2010)

[12] Chen J, Yao B W, Li C, Shi G Q. An improved Hummers method for eco-friendly synthesis of graphene oxide. Carbon 64: 225-229 (2013)

[13] Wang B G, Tang W W, Liu X, Huang Z Y. Synthesis of ionic liquid decorated muti-walled carbon nanotubes as the favorable water-based lubricant additives. Appl Phys A 123(11): 680 (2017)

[14] Min C Y, He Z B, Liu D D, Zhang K, Dong C K. Urea modified fluorinated carbon nanotubes: Unique self-dispersed characteristic in water and high tribological performance as water-based lubricant additives. New J Chem 43(37): 14684-14693 (2019)

[15] Ding M, Lin B, Sui T Y, Wang A Y, Yan S, Yang Q. The excellent anti-wear and friction reduction properties of silica nanoparticles as ceramic water lubrication additives. Ceram Int 44(12): 14901-14906 (2018)

[16] Wu H, Zhao J W, Xia W Z, Cheng X W, He A S, Yun J H, Wang L Z, Huang H, Jiao S H, Huang L, et al. A study of the tribological behaviour of $\mathrm{TiO}_{2}$ nano-additive water-based lubricants. Tribol Int 109: 398-408 (2017)

[17] Wu H, Zhao J W, Cheng X W, Xia W Z, He A S, Yun J H, Wang L Z, Huang H, Jiao S H, Huang L, et al. Friction and wear characteristics of $\mathrm{TiO}_{2}$ nano-additive water-based lubricant on ferritic stainless steel. Tribol Int 117: 24-38 (2018)

[18] Zhang C L, Zhang S M, Song S Y, Yang G B, Yu L G, Wu Z S, Li X H, Zhang P Y. Preparation and tribological properties of surface-capped copper nanoparticle as a waterbased lubricant additive. Tribol Lett 54(1): 25-33 (2014)

[19] He A S, Huang S Q, Yun J H, Wu H, Jiang Z Y, Stokes J, Jiao S H, Wang L Z, Huang H. Tribological performance and lubrication mechanism of alumina nanoparticle waterbased suspensions in ball-on-three-plate testing. Tribol Lett 65(2): 40 (2017)

[20] Jiao Y Y, Liu S Z, Sun Y L, Yue W, Zhang H Y. Bioinspired Surface Functionalization of Nanodiamonds for Enhanced Lubrication. Langmuir 34(41): 12436-12444 (2018) 
[21] Hofmann U, Holst R. The acidic nature and the methylation of graphitoxide. Ber Dtsch Chem Ges 72: 754-771 (1939)

[22] Ruess G. Über das graphitoxyhydroxyd (graphitoxyd). Monatshefte für Chemie und Verwandte Teile Anderer Wissenschaften 76(3-5): 381-417 (1947)

[23] Scholz W, Boehm H. Graphite oxide. 6. Structure of graphite oxide. Zeitschrift Fur Anorganische Und Allgemeine Chemie 369(3-6): 327 (1969)

[24] Nakajima T, Matsuo Y. Formation process and structure of graphite oxide. Carbon 32 (3): 469-475 (1994)

[25] He H Y, Klinowski J, Forster M, Lerf A. A new structural model for graphite oxide. Chem Phys Lett 287(1-2): 53-56 (1998)

[26] Fujita N, Kimura Y. Plate-out efficiency related to oil-inwater emulsions supply conditions on cold rolling strip. Proc Inst Mech Eng, Part J: J Eng Tribol 227(5): 413-422 (2013)

[27] Fujita N, Kimura Y, Kobayashi K, Itoh K, Amanuma Y, Sodani Y. Dynamic control of lubrication characteristics in high speed tandem cold rolling. J Mater Process Technol 229: 407-416 (2016)

[28] Schmid S R, Wilson W R D. Lubrication mechanisms for oil-in-water emulsions. Lubr Eng 52(2): 168-175 (1996)

[29] Min C Y, Zhang Q Q, Shen C, Liu D D, Shen X J, Song H J, Li S J, Xu D, Lin X Y, et al. Graphene oxide/carboxylfunctionalized multi-walled carbon nanotube hybrids: Powerful additives for water-based lubrication. RSC $A d v$ 7(52): 32574-32580 (2017)

[30] Zhao J, Mao J Y, Li Y R, He Y Y, Luo J B. Friction-induced nano-structural evolution of graphene as a lubrication additive. Appl Surf Sci 434: 21-27 (2018)

[31] Lee C, Li Q Y, Kalb W, Liu X Z, Berger H, Carpick R W, Hone J. Frictional characteristics of atomically thin sheets. Science 328(5974): 76-80 (2010)

[32] Lee C, Wei X D, Kysar J W, Hone J. Measurement of the elastic properties and intrinsic strength of monolayer graphene. Science 321(5887): 385-388 (2008)

[33] Lin J S, Wang L W, Chen G H. Modification of graphene platelets and their tribological properties as a lubricant additive. Tribol Lett 41(1): 209-215 (2011)

[34] Feng X F, Kwon S, Park J Y, Salmeron M. Superlubric sliding of graphene nanoflakes on graphene. ACS Nano 7(2): 1718-1724 (2013)

[35] Guo Y F, Guo W L, Chen C F. Modifying atomic-scale friction between two graphene sheets: A molecular-forcefield study. Phys Rev B 76(15): 155429 (2007)

[36] Bonelli F, Manini N, Cadelano E, Colombo L. Atomistic simulations of the sliding friction of graphene flakes. Eur Phys J B 70(4): 449-459 (2009)

[37] Yuan R, Li P, Chen L, Yuan J, Xu B H, Sun G Q, Ding E L,
Chen J M. Effects of grafting oxygen atoms on the tribological properties of graphene: Molecular dynamics simulation and experimental analysis. Appl Surf Sci 528: 147045 (2020)

[38] Du S N, Sun J L, Wu P. Preparation, characterization and lubrication performances of graphene oxide- $\mathrm{TiO}_{2}$ nanofluid in rolling strips. Carbon 140: 338-351 (2018)

[39] Huang S Q, He A S, Yun J H, Xu X F, Jiang Z Y, Jiao S H, Huang H. Synergistic tribological performance of a water based lubricant using graphene oxide and alumina hybrid nanoparticles as additives. Tribol Int 135: 170-180 (2019)

[40] Zhang J, Gao X, Xu Q, Ma T B, Hu Y Z, Luo J B. Atomistic insights into friction and wear mechanisms of graphene oxide. Appl Surf Sci 546: 149130 (2021)

[41] Chen X C, Li J J. Superlubricity of carbon nanostructures. Carbon 158: 1-23 (2020)

[42] Ge X Y, Li J J, Luo R, Zhang C H, Luo J B. Macroscale superlubricity enabled by the synergy effect of grapheneoxide nanoflakes and ethanediol. ACS Appl Mater Interfaces 10(47): 40863-40870 (2018)

[43] Ge X Y, Li J J, Wang H D, Zhang C H, Liu Y H, Luo J B. Macroscale superlubricity under extreme pressure enabled by the combination of graphene-oxide nanosheets with ionic liquid. Carbon 151: 76-83 (2019)

[44] Zhao L, Yang H M, Liu C, Xue S Q, Deng Z, Li J S, Zeng $X$ Q. The correlation between molecular structure and tribological properties of graphene oxide with different oxidation degree. Tribol Lett 67(3): 85 (2019)

[45] Singh S, Chen X C, Zhang C H, Tyagi R, Luo J B. Investigation on the lubrication potential of graphene oxide aqueous dispersion for self-mated stainless steel tribo-pair. Vacuum 166: 307-315 (2019)

[46] Xie H M, Jiang B, Dai J H, Peng C, Li C X, Li Q, Pan F S. Tribological behaviors of graphene and graphene oxide as water-based lubricant additives for magnesium alloy/steel contacts. Materials 11(2): 206 (2018)

[47] Elomaa O, Singh V K, Iyer A, Hakala T J, Koskinen J. Graphene oxide in water lubrication on diamond-like carbon vs. stainless steel high-load contacts. Diamond Relat Mater 52: 43-48 (2015)

[48] He A S, Huang S Q, Yun J H, Jiang Z Y, Stokes J, Jiao S H, Wang L Z, Huang H. The pH-dependent structural and tribological behaviour of aqueous graphene oxide suspensions. Tribol Int 116: 460-469 (2017)

[49] Alias A A, Kinoshita H, Nishina Y, Fujii M. Dependence of $\mathrm{pH}$ level on tribological effect of graphene oxide as an additive in water lubrication. Int J Automot Mech Eng 13(1): 3150-3156 (2016)

[50] Meng W X, Sun J L, Wang C L, Wu P. pH-dependent lubrication mechanism of graphene oxide aqueous lubricants 
on the strip surface during cold rolling. Surf Interface Anal 53(4): 406-417 (2021)

[51] Xu X W, Guo P, Li X W, Lee K R, Cui P, Wang A Y. Exploring the tribological behavior of $\mathrm{Ti} / \mathrm{Al}-\mathrm{DLC} / \mathrm{PAO} /$ graphene oxide nanocomposite system. Ceram Int 47(8): 11052-11062 (2021)

[52] Krishnamoorthy K, Veerapandian M, Yun K, Kim S J. The chemical and structural analysis of graphene oxide with different degrees of oxidation. Carbon 53: 38-49 (2013)

[53] Wang X L, Bai H, Shi G Q. Size fractionation of graphene oxide sheets by $\mathrm{pH}$-assisted selective sedimentation. $J \mathrm{Am}$ Chem Soc 133(16): 6338-6342 (2011)

[54] Wu H, Lu W, Shao J J, Zhang C, Wu M B, Li B H, Yang Q H. pH-dependent size, surface chemistry and electrochemical properties of graphene oxide. New Carbon Mater 28(5): 327-335 (2013)

[55] He Y Q, Wu F, Sun X Y, Li R Q, Guo Y Q, Li C B, Zhang L, Xing F B, Wang W, Gao J P. Factors that affect Pickering emulsions stabilized by graphene oxide. ACS Appl Mater Interfaces 5(11): 4843-4855 (2013)

[56] Lin H, Li Y F, Zhu J H. Cross-linked GO membranes assembled with GO nanosheets of differently sized lateral dimensions for organic dye and chromium separation. $J$ Memb Sci 598: 117789 (2020)

[57] Akther N, Yuan Z W, Chen Y, Lim S, Phuntsho S, Ghaffour $\mathrm{N}$, Matsuyama H, Shon H. Influence of graphene oxide lateral size on the properties and performances of forward osmosis membrane. Desalination 484: 114421 (2020)

[58] Xu L N, Zhao J, Liu Z M, Wang Z Y, Yu K Q, Xing B S. Cleavage and transformation inhibition of extracellular antibiotic resistance genes by graphene oxides with different lateral sizes. Sci Total Environ 695: 133932 (2019)

[59] Lee H, Lee N, Seo Y, Eom J, Lee S W. Comparison of frictional forces on graphene and graphite. Nanotechnology 20(32): 325701 (2009)

[60] Cho D H, Wang L, Kim J S, Lee G H, Kim E S, Lee S, Lee $\mathrm{S}$ Y, Hone J, Lee C. Effect of surface morphology on friction of graphene on various substrates. Nanoscale 5(7): 3063-3069 (2013)

[61] Filleter T, McChesney J L, Bostwick A, Rotenberg E, Emtsev K V, Seyller T, Horn K, Bennewitz R. Friction and dissipation in epitaxial graphene films. Phys Rev Lett 102(8): 086102 (2009)

[62] Filleter T, Bennewitz R. Structural and frictional properties of graphene films on $\mathrm{SiC}(0001)$ studied by atomic force microscopy. Phys Rev B 81(15): 155412 (2010)

[63] Zhang Q, Diao D F, Kubo M. Nanoscratching of multi-layer graphene by molecular dynamics simulations. Tribol Int $\mathbf{8 8}$ : 85-88 (2015)
[64] Ye Z J, Tang C, Dong Y L, Martini A. Role of wrinkle height in friction variation with number of graphene layers. J Appl Phys 112(11): 116102 (2012)

[65] Xu L, Ma T B, Hu Y Z, Wang H. Vanishing stick-slip friction in few-layer graphenes: The thickness effect. Nanotechnology 22(28): 285708 (2011)

[66] Kwon S, Lee K E, Lee H, Koh S J, Ko J H, Kim Y H, Kim S O, Park J Y. The effect of thickness and chemical reduction of graphene oxide on nanoscale friction. $J$ Phys Chem B 122(2): 543-547 (2018)

[67] Lee H, Son N, Jeong H Y, Kim T G, Bang G S, Kim J Y, Shim G W, Shim G W, Goddeti K C, Kim J H, et al. Friction and conductance imaging of $\mathrm{sp}^{2}$ - and $\mathrm{sp}^{3}$-hybridized subdomains on single-layer graphene oxide. Nanoscale 8(7): 4063-4069 (2016)

[68] Kinoshita H, Nishina Y, Alias A A, Fujii M. Tribological properties of monolayer graphene oxide sheets as waterbased lubricant additives. Carbon 66: 720-723 (2014)

[69] Gan C L, Liang T, Li X P, Li W, Li H, Fan X Q, Zhu M H. Ultra-dispersive monolayer graphene oxide as water-based lubricant additive: Preparation, characterization and lubricating mechanisms. Tribol Int 155: 106768 (2021)

[70] Guo P F, Chen L, Wang J J, Geng Z R, Lu Z B, Zhang G A. Enhanced tribological performance of aminated nano-silica modified graphene oxide as water-based lubricant additive. ACS Appl Nano Mater 1(11): 6444-6453 (2018)

[71] Huang S Q, Li X L, Yu B W, Jiang Z Y, Huang H. Machining characteristics and mechanism of $\mathrm{GO} / \mathrm{SiO}_{2}$ nanoslurries in fixed abrasive lapping. $J$ Mater Process Technol 277: 116444 (2020)

[72] Lv T, Huang S Q, Hu X D, Ma Y L, Xu X F. Tribological and machining characteristics of a minimum quantity lubrication (MQL) technology using $\mathrm{GO} / \mathrm{SiO}_{2}$ hybrid nanoparticle water-based lubricants as cutting fluids. Int $J$ Adv Manuf Technol 96(5-8): 2931-2942 (2018)

[73] Wu P, Chen X C, Zhang C H, Luo J B. Synergistic tribological behaviors of graphene oxide and nanodiamond as lubricating additives in water. Tribol Int 132: 177-184 (2019)

[74] He A S, Huang S Q, Yun J H, Jiang Z Y, Stokes J R, Jiao S H, Wang L Z, Huang H. Tribological characteristics of aqueous graphene oxide, graphitic carbon nitride, and their mixed suspensions. Tribol Lett 66(1): 42 (2018)

[75] Wu Y L, Zeng X Q, Ren T H, de Vries E, van der Heide E. The emulsifying and tribological properties of modified graphene oxide in oil-in-water emulsion. Tirbol Int 105: 304-316 (2017)

[76] Sun J L, Du S N, Meng Y N, Wu P. Analysis of tribological properties of triethanolamine modified graphene oxide additive in water. $J$ Tribol 141(1): 014501 (2019) 
[77] Yang H M, Li J S, Zeng X Q. Correlation between molecular structure and interfacial properties of edge or basal plane modified graphene oxide. ACS Appl Nano Mater 1(6): 2763-2773 (2018)

[78] Yang H M, Zhao L, Xue S Q, Deng Z, Li J S, Zeng X Q. Branch-chain length modulated graphene oxides for regulating the physicochemical and tribophysical properties of pickering emulsions. Colloids Surf A: Phys Eng Aspects 579: 123703 (2019)

[79] Yang H M, Xue S Q, Zhou J L, Li J S, Zeng X Q. Interfacial assembly behavior of alkylamine-modulated graphene oxide with different oxidation degrees. Langmuir 35(40): 1293612946 (2019)

[80] Berman D, Erdemir A, Sumant A V. Few layer graphene to reduce wear and friction on sliding steel surfaces. Carbon 54: 454-459 (2013)

[81] Saravanakumar N, Prabu L, Karthik M, Rajamanickam A. Experimental analysis on cutting fluid dispersed with silver nano particles. J Mech Sci Technol 28(2): 645-651 (2014)

[82] Yadgarov L, Petrone V, Rosentsveig R, Feldman Y, Tenne $\mathrm{R}$, Senatore A. Tribological studies of rhenium doped fullerene-like $\mathrm{MoS}_{2}$ nanoparticles in boundary, mixed and elasto-hydrodynamic lubrication conditions. Wear 297(1-2): 1103-1110 (2013)

[83] Yang G B, Chai S T, Xiong X J, Zhang S M, Yu L G, Zhang P Y. Preparation and tribological properties of surface modified $\mathrm{Cu}$ nanoparticles. Trans Nonferrous Met Soc China 22(2): 366-372 (2012)

[84] Sammaiah A, Dai Q W, Huang W, Wang X L. Synthesis of $\mathrm{GO}-\mathrm{Fe}_{3} \mathrm{O}_{4}$-based ferrofluid and its lubrication performances. Proc Inst Mech Eng, Part J: J Eng Tribol 234(7): (2020)

[85] Cho M H, Bahadur S. Friction and wear of polyphenylene sulfide composites filled with micro and nano $\mathrm{CuO}$ particles in water-lubricated sliding. Tribol Lett 27(1): 45-52 (2007)

[86] Iijima S. Helical microtubules of graphitic carbon. Nature 354(6348): 56-58 (1991)

[87] Novoselov K S, Geim A K, Morozov S V, Jiang D, Zhang Y, Dubonos S V, Grigorieva I V, Firsov A A. Electric field effect in atomically thin carbon films. Science 306(5696): 666-669 (2004)

[88] Miyoshi K, Street Jr K W, Wal R L V, Andrews R, Sayir A. Solid lubrication by multiwalled carbon nanotubes in air and in vacuum. Tribol Lett 19(3): 191-201 (2005)

[89] Dreyer D R, Park S, Bielawski C W, Ruoff R S. The chemistry of graphene oxide. Chem Soc Rev 39(1): 228-240 (2010)

[90] Geim A K, Novoselov K S. The rise of graphene. Nature Mater 6(3): 183-191 (2007)
[91] Deng Z, Smolyanitsky A, Li Q Y, Feng X Q, Cannara R J. Adhesion-dependent negative friction coefficient on chemically modified graphite at the nanoscale. Nat Mater 11(12): 1032-1037 (2012)

[92] Chu P K, Li L H. Characterization of amorphous and nanocrystalline carbon films. Mater Chem Phys 96(2-3): 253-277 (2006)

[93] Yang H M, Li J S, Zeng X Q. Tribological behavior of nanocarbon materials with different dimensions in aqueous systems. Friction 8(1):29-46 (2020)

[94] Shanmugharaj A M, Yoon J H, Yang W J, Ryu S H. Synthesis, characterization, and surface wettability properties of amine functionalized graphene oxide films with varying amine chain lengths. J Colloid Interface Sci 401: 148-154 (2013)

[95] Fei X M, Xia L, Chen M Q, Wei W, Luo J, Liu X Y. Preparation and application of water-in-oil emulsions stabilized by modified graphene oxide. Materials 9(9): 731 (2016)

[96] Li H L, Xue S Q, Shang Y Z, Li J S, Zeng X Q. Research and application progress based on the interfacial properties of graphene oxide. Adv Mater Interfaces 7(21): 2000881 (2020)

[97] Gan C L, Liang T, Li W, Fan X Q, Zhu M H. Amineterminated ionic liquid modified graphene oxide/copper nanocomposite toward efficient lubrication. Appl Surf Sci 491: 105-115 (2019)

[98] Singh S, Samanta S, Das A K, Sahoo R R. Tribological investigation of Ni-graphene oxide composite coating produced by pulsed electrodeposition. Surf Interfaces 12: 61-70 (2018)

[99] Tong L B, Zhang J B, Xu C, Wang X, Song S Y, Jiang Z H, Kamado S, Cheng L R, Zhang H J. Enhanced corrosion and wear resistances by graphene oxide coating on the surface of Mg-Zn-Ca alloy. Carbon 109: 340-351 (2016)

[100] Wang Y, Pu J B, Xia L, Ding J N, Yuan N Y, Zhu Y Y, Cheng G G. Fabrication and tribological study of graphene oxide/multiply-alkylated cyclopentanes multilayer lubrication films on Si substrates. Tribol Lett 53(1): 207-214 (2014)

[101] Samanta S, Singh S, Sahoo R R. Covalently grafting of self-assembled functionalized graphene oxide multilayer films on Si substrate for solid film lubrication. Thin Solid Films 683: 16-26 (2019)

[102] Liu Y F, Chen X C, Li J J, Luo J B. Enhancement of friction performance enabled by a synergetic effect between graphene oxide and molybdenum disulfide. Carbon 154: 266-276 (2019)

[103] Wang M J, Li Z P, Hou K M, Wang J Q, Yang S R. Balancing oxygen-containing groups and structural defects for optimizing macroscopic tribological properties of graphene oxide coating. Appl Surf Sci 516: 146122 (2020) 
[104] Li X, Lu H L, Guo J D, Tong Z, Dong G N. Synergistic water lubrication effect of self-assembled nanofilm and graphene oxide additive. Appl Surf Sci 455: 1070-1077 (2018)

[105] Cao F X, Jiang P F, Wang J Z, Yan F Y. Tribological properties of poly(phthalazione ether sulfone ketone) composites reinforced with glass fabric modified by graphene oxide depositing. Surf Interface Anal 50(6): 667-673 (2018)

[106] Sadeghi M, Kharaziha M, Salimijazi H R. Double layer graphene oxide-PVP coatings on the textured $\mathrm{Ti}_{6} \mathrm{Al}_{4} \mathrm{~V}$ for improvement of frictional and biological behavior. Surf Coat Technol 374: 656-665 (2019)

[107] Wu F, Zhao W J, Chen H, Zeng Z X, Wu X D, Xue Q J. Interfacial structure and tribological behaviours of epoxy resin coating reinforced with graphene and graphene oxide. Surf Interface Anal 49(2): 85-92 (2017)

[108] Maheshkumar K V, Krishnamurthy K, Sathishkumar P, Sahoo S, Uddin E, Pal S K, Rajasekar R. Research updates on graphene oxide-based polymeric nanocomposites. Polym Compos 35(12): 2297-2310 (2014)

[109] Li Y Q, Wang Q H, Wang T M, Pan G Q. Preparation and tribological properties of graphene oxide/nitrile rubber nanocomposites. J Mater Sci 47(2): 730-738 (2012)

[110] An Y F, Tai Z X, Qi Y Y, Yan X B, Liu B, Xue Q J, Pei J Y. Friction and wear properties of graphene oxide/ultrahighmolecular-weight polyethylene composites under the lubrication of deionized water and normal saline solution. J Appl Polym Sci 131(1): 39640 (2014).

[111] Yuan R, Ju P F, Wu Y P, Ji L, Li H X, Chen L, Zhou H D, Chen J M. Silane-grafted graphene oxide improves wear and corrosion resistance of polyimide matrix: Molecular dynamics simulation and experimental analysis. $J$ Mater Sci 54(16): 11069-11083 (2019)

[112] Vadivel H S, Golchin A, Emami N. Tribological behaviour of carbon filled hybrid UHMWPE composites in water. Tribol Int 124: 169-177 (2018)

[113] Yin X, Wu J, Li C, Lu X H, Feng X, Shi Y J. Right way of using graphene oxide additives for water-lubricated PEEK: Adding in polymer or water? Tribol Lett 66(3): 103 (2018)

[114] Min C Y, He Z B, Liang H Y, Liu D D, Dong C K, Song H J, Huang Y D. High mechanical and tribological performance of polyimide nanocomposite reinforced by fluorinated graphene oxide. Polym Compos 41(4): 16241635 (2020)

[115] Pervaiz S, Kannan S, Kishawy H A. An extensive review of the water consumption and cutting fluid based sustainability concerns in the metal cutting sector. $J$ Clean Prod 197: 134-153 (2018)
[116] Li X L, Huang S Q, Wu Y Q, Huang H. Performance evaluation of graphene oxide nanosheet water coolants in the grinding of semiconductor substrates. Prec Eng 60: 291-298 (2019)

[117] Yi S, Li J J, Zhu J H, Wang X Z, Mo J, Ding S L. Investigation of machining Ti-6Al-4V with graphene oxide nanofluids: Tool wear, cutting forces and cutting vibration. J Manuf Processes 49: 35-49 (2020)

[118] Yi S, Mo J, Ding S L. Experimental investigation on the performance and mechanism of graphene oxide nanofluids in turning Ti-6Al-4V. J Manuf Processes 43: 164-174 (2019)

[119] Xue S Q, Cen Y M, Yang H M, Honda T, Nakanishi Y, Zhang L, Zhang B H, Zeng X Q. The enhanced lubrication of water-based cutting fluid by functionalized GO. Tribol Lett 68(3): 93 (2020)

[120] Moro T, Takatori Y, Ishihara K, Konno T, Takigawa Y, Matsushita T, Chung U I, Nakamura K, Kawaguchi H. Surface grafting of artificial joints with a biocompatible polymer for preventing periprosthetic osteolysis. Nat Mater 3(11): 829-836 (2004)

[121] Xu H D, Chen K, Zhang D K, Yang X H. Torsional friction behavior of the contact interface between the materials of an artificial knee joint replacement. J Biomater Sci, Polym Ed 29(5): 562-581 (2018)

[122] Learmonth I D, Young C, Rorabeck C. The operation of the century: Total hip replacement. Lancet 370(9597): 1508-1519 (2007)

[123] Park C, Park S, Kim J, Han A, Ahn S, Min S K, Jae H J, Chung J W, Lee J H, Jung H D, et al. Enhanced endothelial cell activity induced by incorporation of nano-thick tantalum layer in artificial vascular grafts. Appl Surf Sci 508: 144801 (2020)

[124] Geng Z, Li Z Y, Cui Z D, Wang J, Yang X J, Liu C S. Novel bionic topography with MiR-21 coating for improving bone-implant integration through regulating cell adhesion and angiogenesis. Nano Lett 20(10): 7716-7721 (2020)

[125] Lee A, He L H, Lyons K, Swain M V. Tooth wear and wear investigations in dentistry. J Oral Rehabil 39(3): 217-225 (2012)

[126] Lewis R, Dwyer-Joyce R S. Wear of human teeth: A tribological perspective. Proc Inst Mech Eng, Part $J: J$ Eng Tribol 219(1): 1-18 (2005)

[127] Shellis R P, Addy M. The interactions between attrition, abrasion and erosion in tooth wear. Monogr Oral Sci $\mathbf{2 5}$ $32-45$ (2014)

[128] Van Der Heide E, Zeng X, Masen M A. Skin tribology: Science friction? Friction 1(2): 130-142 (2013) 
[129] Lin L, Li J, Zeng X. The development of physical skin model for biomechanical applications. J Soc Biomech 41(3): 129-136 (2017)

[130] Shao W, Liu H, Liu X F, Wang S X, Zhang R. Antibacterial performances and biocompatibility of bacterial cellulose/graphene oxide composites. RSC Adv 5(7): 47954803 (2015)

[131] Mugesh S, Arun R, Arunkumar K, Murugan M. Synthesis of biogenic copper nanoparticles embedded in graphene oxide-chitosan composite and its anti-bacterial and cytotoxic activities. J Nanosci Nanotechnol 19(5): 2625-2632 (2019)

[132] Abdelhalim A O E, Sharoyko V V, Meshcheriakov A A, Martynova S D, Ageev S V, Iurev G O, Al Mulla H, Petrov A V, Solovtsova I L, Vasina L V, et al. Reduction and functionalization of graphene oxide with L-cysteine:

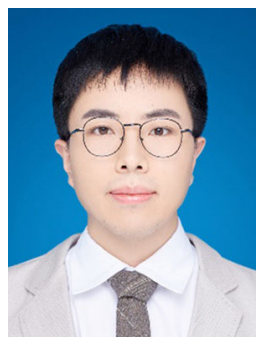

Shaoqing XUE. He received bachelor's degree from Zhengzhou University in 2018. Now he is studying for master's degree at Shanghai Advanced Research

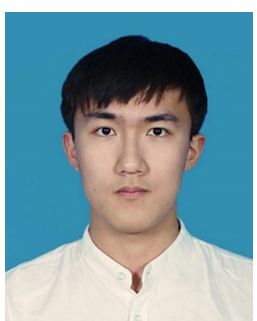

Hanglin LI. He received bachelor's degree from Nanjing University of Information Science and Technology in 2018. Now he is studying for master's degree at Shanghai

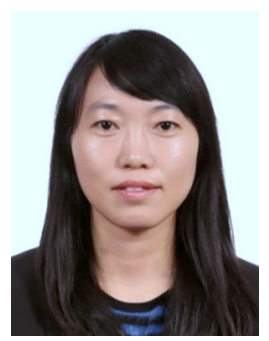

Xiangqiong ZENG. She received Ph.D. degree in material science in 2006 from Shanghai Jiao Tong University. She worked as staff scientist at Johnson \& Johnson Consumer Group and then as assistant professor at the University
Synthesis, characterization and biocompatibility. Nanomedicine: Nanotechnol Biol Med 29: 102284 (2020)

[133] Xu M, Zhu J Q, Wang F F, Xiong Y J, Wu Y K, Wang Q $\mathrm{Q}$, Weng J, Zhang Z H, Chen W, Liu S J. Improved in vitro and in vivo biocompatibility of graphene oxide through surface modification: Poly(Acrylic Acid)-functionalization is superior to PEGylation. Acs Nano 10(3): 3267-3281 (2016)

[134] Pinto A M, Gonçalves I C, Magalhães F D. Graphenebased materials biocompatibility: A review. Colloids Surf B: Biointerfaces 111: 188-202 (2013)

[135] Ren S S, Lu H L, Guo J D, Li Y, Li X, Li J H, Dong G N. Graphene oxide/poly(ethylene glycol)/chitosan gel with slow-release lubrication applied on textured surface. $J$ Appl Polym Sci 135(10): 45818 (2018)

Institute, Chinese Academy of Sciences. Currently, he is working on the synthesis and functionalization of graphene oxides (GO), exploring the tribology and interfacial behaviors of GO-based materials.

Advanced Research Institute, Chinese Academy of Sciences. His research focus is to explore the interfacial properties of GO and functionalized GO, aiming to figure out the oil-water interface behavior of $2 \mathrm{D}$ particles.

of Twente. Currently, she is a full professor at Shanghai Advanced Research Institute, Chinese Academy of Sciences, working on functional interface materials, including active control of friction and wear by surface and interface design and by additive and emulsion development. 